\title{
Review Article \\ Design and Synthesis of Nanostructured Materials for Sensor Applications
}

\author{
Naumih M. Noah \\ School of Pharmacy and Health Sciences, United States International University-Africa (USIU-A), P.O. Box 14634-00800, \\ Nairobi, Kenya \\ Correspondence should be addressed to Naumih M. Noah; mnoah@usiu.ac.ke
}

Received 21 August 2020; Revised 28 September 2020; Accepted 16 October 2020; Published 31 October 2020

Academic Editor: Sheng-Joue Young

Copyright (C) 2020 Naumih M. Noah. This is an open access article distributed under the Creative Commons Attribution License, which permits unrestricted use, distribution, and reproduction in any medium, provided the original work is properly cited.

\begin{abstract}
There has been an increasing demand for the development of sensor devices with improved characteristics such as sensitivity, low cost, faster response, reliability, rapider recovery, reduced size, in situ analysis, and simple operation. Nanostructured materials have shown great potential in improving these properties for chemical and biological sensors. There are different nanostructured materials which have been used in manufacturing nanosensors which include nanoscale wires (capability of high detection sensitivity), carbon nanotubes (very high surface area and high electron conductivity), thin films, metal and metal oxide nanoparticles, polymer, and biomaterials. This review provides different methods which have been used in the synthesis and fabrication of these nanostructured materials followed by an extensive review of the recent developments of metal, metal oxides, carbon nanotubes, and polymer nanostructured materials in sensor applications.
\end{abstract}

\section{Introduction}

Nanostructures are materials which have a nanometer scale sizes in one, two, or three dimensions typically between 1 and $100 \mathrm{~nm}$ range [1-3]. They bring forth innovative material applications due to their superior physicochemical and plasmonic properties, and as such, they have generated a great deal of interest from basic scientific research to commercial development [1]. They have obtained prominence in technological developments due to their extraordinary physicochemical properties such as their melting points, electrical and thermal conductivities, light absorption and scattering properties, optical sensitivity, catalytic activity, and wettability resulting in their significantly enhanced performance over their bulk counterparts $[2,4]$. These properties have enabled new applications ranging from energy conservation and structural strength enhancement to antimicrobial characteristics and self-cleaning surfaces as well as in sensor applications $[1,4]$. Generally, nanostructures are divided into surface and bulk nanostructures, where the surface nanostructures refer to nanoscale patterns created on the surface of a substrate while bulk nanostructures refer to individual nanomaterial's or an assembly of nanomaterial's [1]. There is a wide variety of nanostructured materials with different dimensions which range from zero-dimensional (0D) nanoparticles, one-dimensional (1D) nanorods and nanowires, twodimensional (2D) nanosheets and films, three-dimensional (3D) polycrystals and ultraporous nanostructures, and nanoscaffolds $[3,5]$ as illustrated in Figure 1.

The most promising features of these structures are their size-dependent properties. For example, metallic nanoparticles exhibit tunable radiation and absorption wavelength depending on their aspect ratio [6] and coating [7]. These unique properties are attributed to the phenomenon called localized surface plasmon resonance (LPSR). Each particle can effectively produce photoluminescence equivalent to a million dye molecules. Additionally, they are photo stable and do not suffer from photo bleaching [8]. Owing to their superior optical properties, they can produce better signal over ordinary dye molecules. After coating with probe molecules, the optical properties of nanostructures allow the detection of specific target molecules. Numerous physical and chemical 


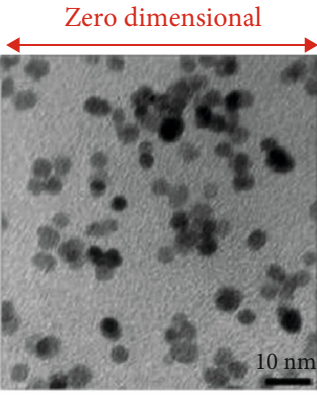

(a)

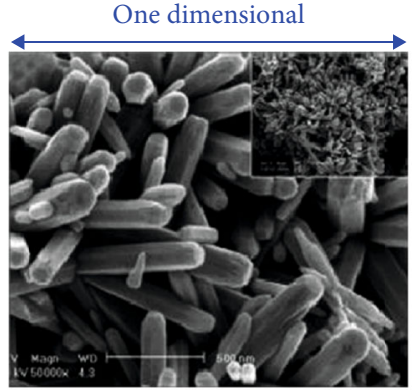

(b)

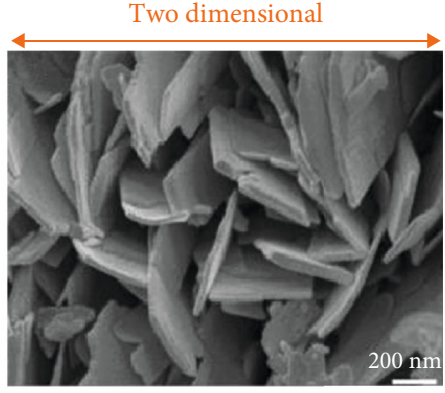

(c)

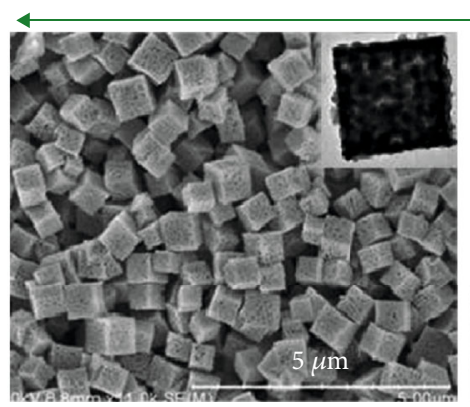

(d)

Three dimensional

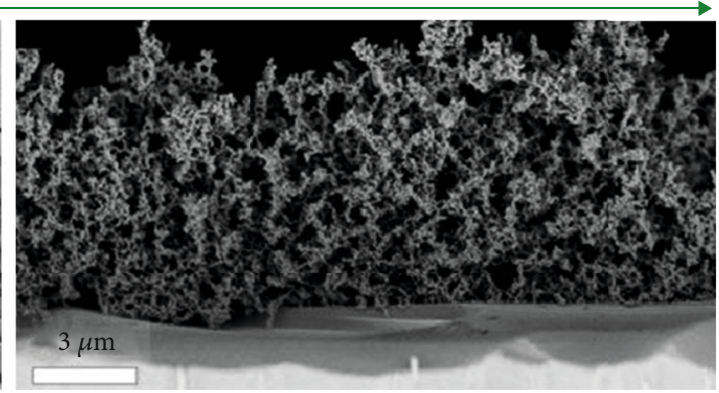

(e)

Figure 1: (a) Typical TEM image of ZnO quantum dots (QDs) obtained through a wet synthesis method. (b) SEM images of ZnO nanorods. (c) SEM image of $\mathrm{ZnO}$ nanosheets formed through a simple mixed hydrothermal synthesis method. (d) SEM images of acid-washed porous $\mathrm{SnO}_{2}$ microcubes after calcination at $900^{\circ} \mathrm{C}$ for $2 \mathrm{~h}$. Inset: TEM image of the as-prepared porous $\mathrm{SnO}_{2}$ microcubes. (e) $\mathrm{ZnO}$ ultra porous film made by flame spray pyrolysis. Adapted from [5], an open access article.

methods have been developed for the fabrication of nanostructured materials [9-12], and they are described in the next section.

\section{Fabrication of Nanostructured Materials}

Various syntheses and processing techniques have been established for the fabrication of nanostructured materials with a higher degree tailored specifically to the material to be produced which might be considered to be more restrictive than the conventional production methods [13]. Generally, the fabrication of nanostructured materials is considered to proceed via two main strategies which include the "bottom-up" and "top-down" approaches $[1,13]$. The difference between these two general strategies is based on the processes involved in the construction of the nanostructures [14]. In the bottom-up approach, a structure is normally built up of small units while in top-down approach, a larger unit is reduced in size to a finished structure [1] as shown in Figure 2. While the top-down approach comprises a few viable fabrication techniques which stem from experience and technology developed in other industries, many fabrication methods use the bottom up approach where building blocks of nanoparticles or clusters are first prepared by an appropriate technique and then assembled into composites, coatings, and layers or consolidated into bulk under well-controlled conditions [13]. The fabrication of nanostructured materials can also be achieved through a combination of the two approaches which are discussed in more details below.
2.1. Top-Down Approach. In top-down approach, large materials are normally deconstructed by a chain of physical and chemical processes $[1,3,14]$. The physical top-down approach employs the use of photons, electrons, and ions while the chemical top-down strategy relies essentially on chemical reactions that are brought about by chemical etchants or by application of heat [14]. This approach can be used to fabricate a varied selection of devices with high reliability and integrity and is therefore common in the semiconductor device industry [3]. Many novel structures such as nanowires which can be used to detect biological samples without labelling have been fabricated using this approach [15]. Nanopores used to detect and measure biophysical properties of deoxyribonucleic acid (DNA), proteins, and other molecules passing through the nanopores have also been fabricated using the top-down approach [16]. The basic fabrication steps in top-down approach include (i) lithography, (ii) laser ablation, (iii) chemical etching, (iv) milling process, and (v) thermal decomposition which are described in more details below.

2.1.1. Lithography. Lithography is a physical top-down approach which employs the use of photons (optical lithography), electrons (electron beam lithography), and ions (ion beam lithography) to fabricate nanostructures [14]. It has been a method of choice for producing patterned nanostructures in the microelectronics industry since it transfers a pattern from a mask on a substrate $[3,14]$. The most common method is optical lithography which uses ultraviolet light to transfer the desired pattern from a mask to a light-sensitive 


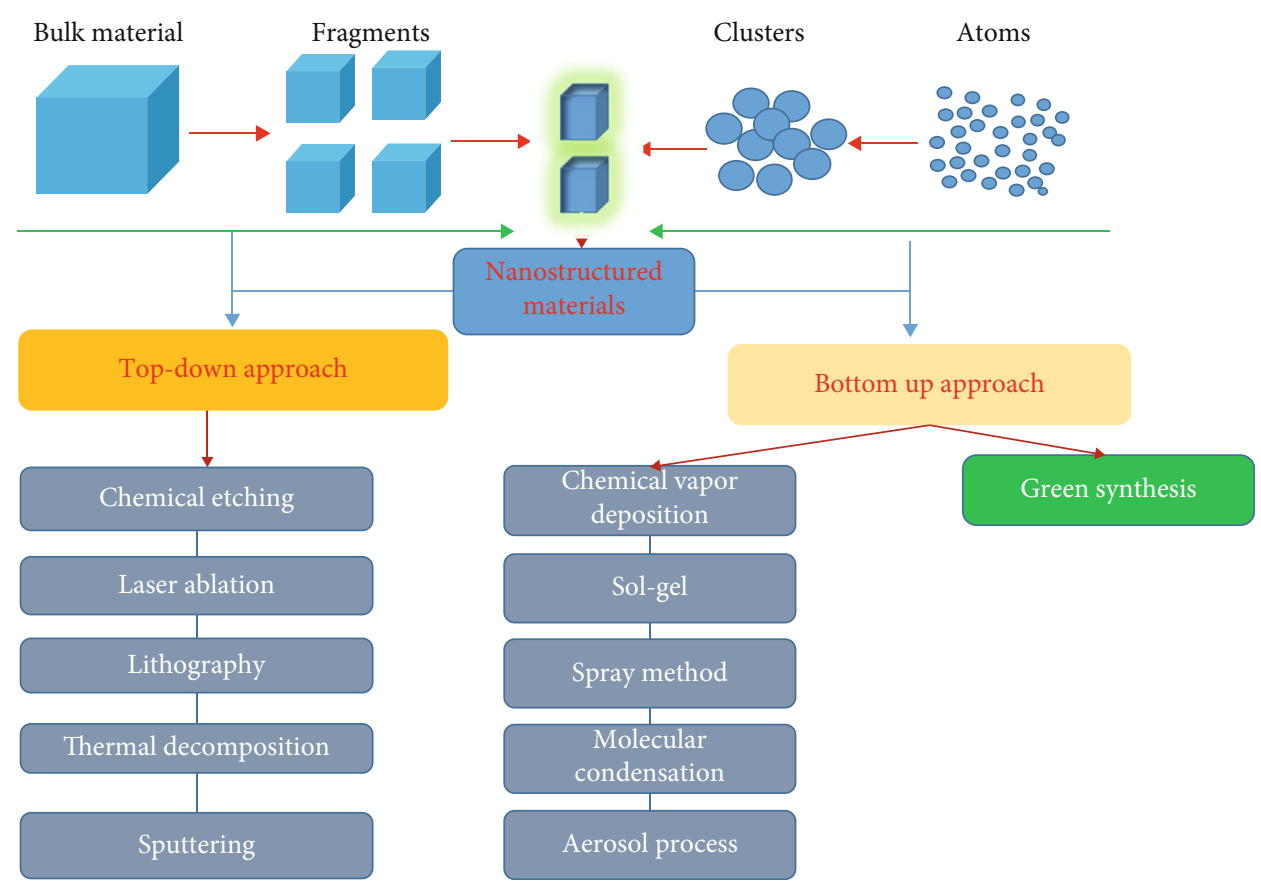

FIGURE 2: A schematic representation of the top-down and bottom-up approaches for the fabrication of nanostructures.

material known as photoresist that coats the semiconductor substrate $[3,14]$. The substrate undergoes changes in chemical composition when exposed to a specific wavelength of light through the mask to create a pattern which is subsequently transferred to the substrate often by etching $[1,3$, $14]$ as illustrated in Figure 3. Electron beam lithography on the other hand uses electrons instead of photons to achieve nanostructures at a resolution beyond the diffraction limit of light $[14,17]$. It is a maskless techniques which generates the pattern directly using a tightly focused beam of accelerated electrons to scan the substrate coated with an electron-reactive resist [14]. The ion beam lithography [18] and laser writing [19] are also maskless approaches which use a focused beam of high energy ions and multiphoton absorption-induced photochemical transformation of the photoresist, respectively.

2.1.2. Chemical/Template Etching. This is a subtractive chemical top-down nanofabrication technique that selectively removes materials from a substrate. It uses a template to direct the chemical etching of a substrate resulting to a nanoscale pattern crafted on the substrate surface. The etching can be done in dry or wet conditions [3, 14]. For example, a silicon substrate as shown in Figure 4 [20] has been fabricated using a block of copolymer template prepared by spin coating a solution of a copolymer consisting of a poly-(4-vinylpyridine) core and a polystyrene corona prepared in toluene on the silicon substrate $[14,20]$. Upon spin coating, the amphiphilic polymer micelles of the copolymer spontaneously selfassembled into a monolayer of pseudohexagonal array on the substrate surface, forming the template $[14,20]$. The nanoscale pattern of the polymer template is then transferred to the underlying substrate by selective etching with an aqueous solution of hydrofluoric acid (HF) [14, 20]. Fluoride-based

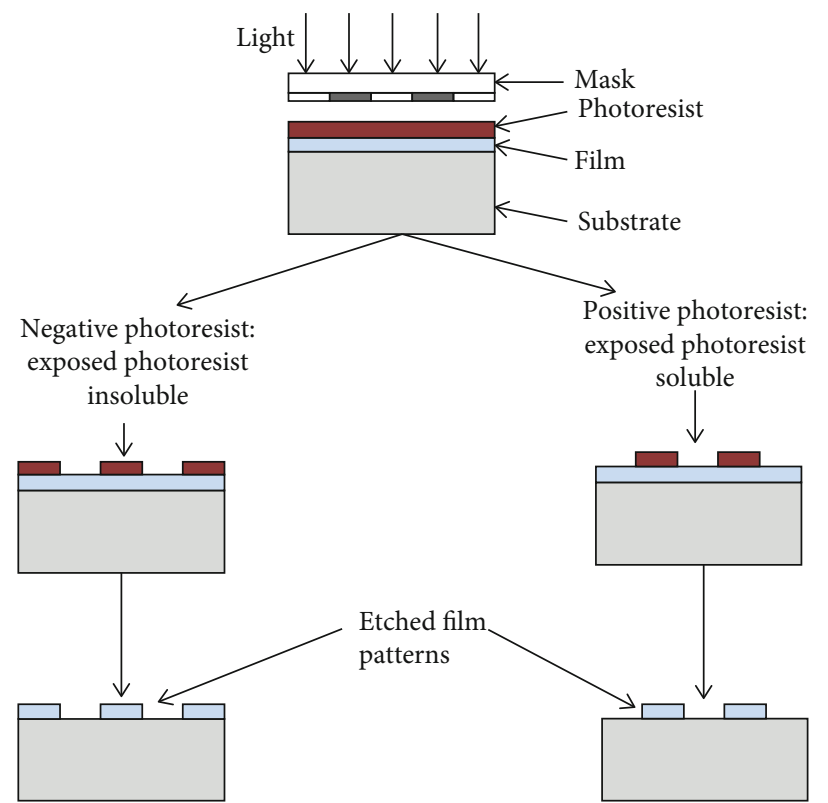

FIGURE 3: A schematic representation of optical lithography using negative and positive photoresist [3].

etching of the silicon surface takes place exclusively beneath the poly-(4-vinylpyridine) cores due to the protonation of the pyridyl groups by $\mathrm{HF}$ that results in selective localization of fluoride ions within the micellar cores $[14,20]$. The silicon etch pit array is finally obtained after removal of the polymer template through ultrasonication in toluene [20]. The resulting etched features on the silicon surface can be functionalized with other materials (e.g., gold nanoparticles), allowing for the generation of more complex architectures [20,21]. 


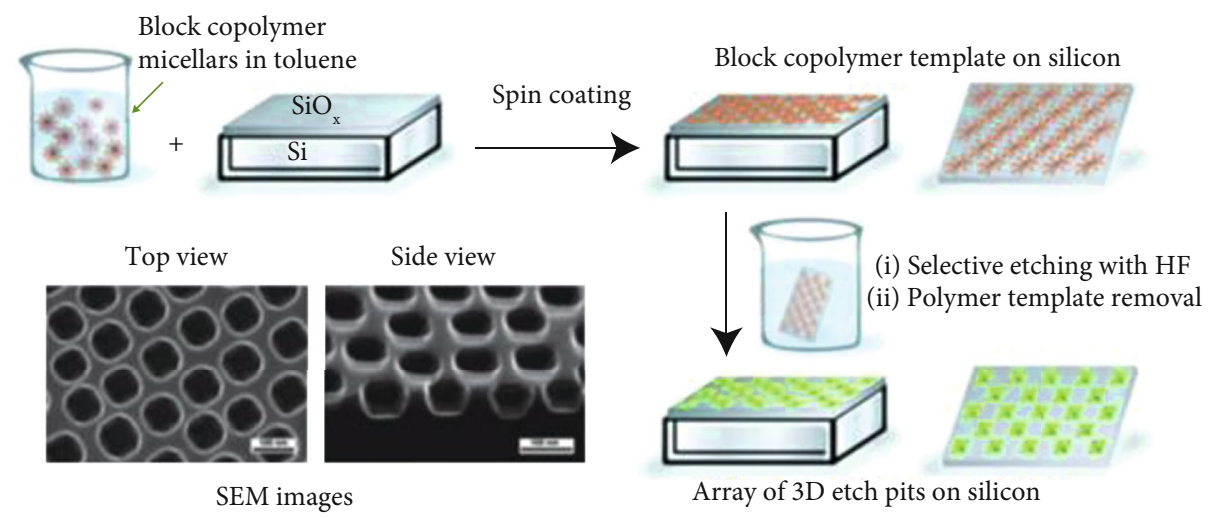

FIGURE 4: A schematic diagram representing the fabrication of a 3D etch pit array on silicon using a block copolymer as a template and an aqueous solution of hydrofluoric acid (HF) as an etchant. SEM images displaying the etch pit arrays on silicon are also shown (scale bar $=100 \mathrm{~nm}$ ). Adapted with permission from ref. [20]. Copyright $($ ) 2007, American Chemical Society.

2.1.3. Thermal Decomposition. Thermal decomposition also known as thermolysis is a process where heat is used to separate chemical bonds in a compound [14]. This process provides a simple one-step strategy to fabricate nanostructures with controlled porosity which is an advantage as compared to other methods. This method was demonstrated by Yu and team where they used it to fabricate nanoporous cadmium oxide $(\mathrm{CdO})$ from cadmium carbonate $\left(\mathrm{CdCO}_{3}\right)$ microcrystals [22]. In their work, high-quality $\mathrm{CdCO}_{3}$ microcrystals were transformed as they were continuously heat treated at $500^{\circ} \mathrm{C}$ for 30 minutes. This led to a decomposition process which began at the sharp edges and corners and continued to the flat surfaces of the crystals resulting in a core-shell microstructure wherein the newly formed $\mathrm{CdO}$ densely coated the partially decomposed $\mathrm{CdCO}_{3}$ crystals releasing carbon dioxide $\left(\mathrm{CO}_{2}\right)$ [22] as illustrated in Figure 5. As thermolysis continued, more and more $\mathrm{CO}_{2}$ molecules accumulated inside the microstructure until the pressure was high enough that tiny pores nucleated to allow the escape of the trapped gas. These tiny pores eventually grew into continuous channels as the decomposition of $\mathrm{CdCO}_{3}$ went to completion [22].

2.1.4. Selective Dealloying. Selective dealloying normally produces nanoporous metals by utilizing chemical or electrochemical reactions to remove the most chemically active metal in the alloy. As the less noble metal is removed, atoms of the more noble metal reorganize into a $3 \mathrm{D}$ network of pores/channels and ligaments [14].

2.1.5. Mechanical Milling. A mechanical milling technique has been utilized to produce amorphous and nanocrystalline alloys as well as metal/nonmetal nanocomposite materials by milling and post annealing, of elemental or compound powders in an inert atmosphere [23]. It is a nonequilibrium processing technique whereby different elemental powders are milled in an inert atmosphere to create one mixed powder with the same composition as the constituents [23]. Mechanical milling has been utilized to synthesize various nanoalloys and many nanocomposites in very high yield. The mechanical milling has been utilized for the synthesis of nanomater- ials either by milling and postannealing or by mechanical activation and then applying some other process on these activated materials [23].

2.2. Bottom-Up Approach. The bottom-up approach involves the assembly of the building blocks (atoms or molecules) into nanostructured arrays due to attractive forces $[1,3,24]$. This approach has the potential to generate functional multicomponent devices by self-assembly of the atoms and molecules without wasting them or the need for eliminating parts of the system [17]. The assembly of the elementary building blocks is usually manipulated by either physical aggregation, chemical reaction, or use of templates $[3,24]$ where controlled chemical reactions manipulate the building blocks to self-assemble and make nanostructures such as nanotubes, nanoribbons, and quantum dots $[1,25,26]$. This approach has the potential to assemble nanostructured materials where the top-down approach fails though one of its major challenges is to ensure predefined structures with precise shapes and sizes [3]. Some of the most common bottom-up nanofabrication methods are described below.

2.2.1. Chemical Vapor Deposition. Chemical vapor deposition (CVD) is a process where a substrate is exposed to one or more volatile precursors, which react and/or decompose on the surface of the substrate to produce a thin film deposit $[27,28]$. By changing various experimental conditions such as the substrate material, substrate temperature, and composition of the reaction gas mixture, total pressure gas flows and other materials with a wide range of physical, tribological, and chemical properties can be produced $[27,28]$ as illustrated in Figure 6 [29]. All chemical vapour deposition reactions involve a number of steps. The main steps are as follows: precursor, generation of active gaseous reactant species; transport, delivering the precursor into the reaction chamber; adsorption of the precursor onto the hot surface; decomposition of the precursor to give the atom needed for the film and organic waste; migration of atoms to a strong binding site; nucleation that leads to the growth of the thin film; desorption of unwanted side products; and removal of unwanted products $[30,31]$. However, it is possible to 

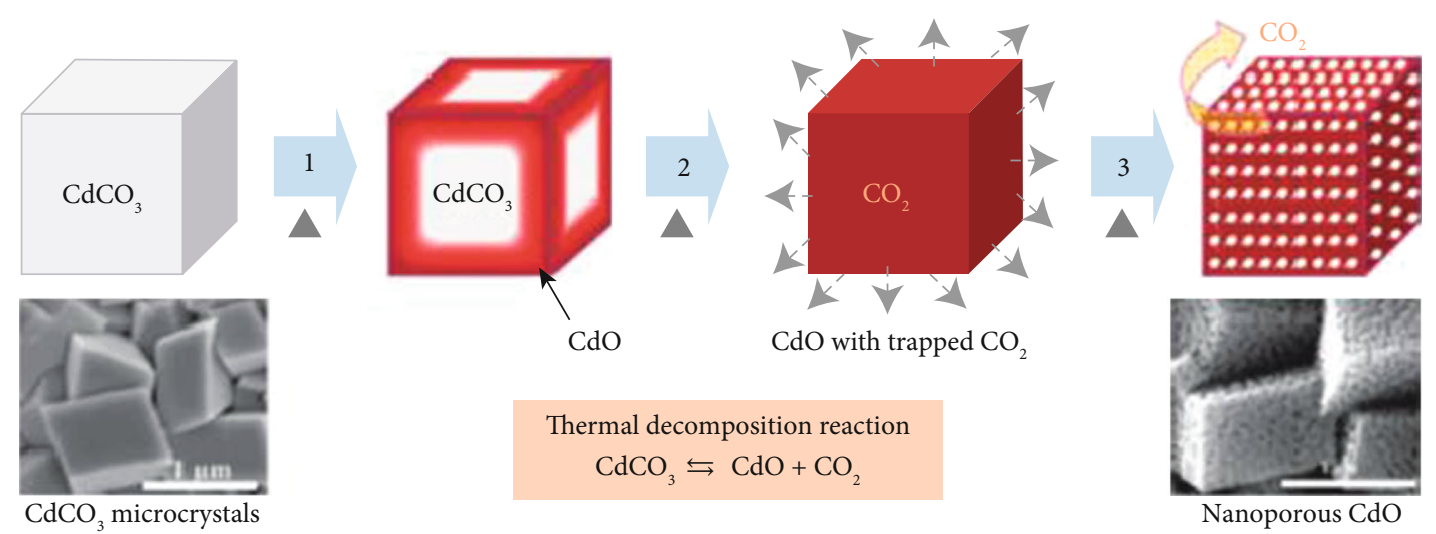

Figure 5: A schematic illustration of the mechanism of formation of nanoporous $\mathrm{CdO}$ upon thermal decomposition of high-quality $\mathrm{CdCO}_{3}$ microcrystals at $500^{\circ} \mathrm{C}$ for $30 \mathrm{~min}$. Also shown are the SEM images of the starting $\mathrm{CdCO}_{3}$ microcrystals and the resulting nanoporous $\mathrm{CdO}$ (scale bar $=1 \mathrm{~mm})$. Reproduced with permission from ref. [22]. Copyright @ 2007, American Chemical Society.

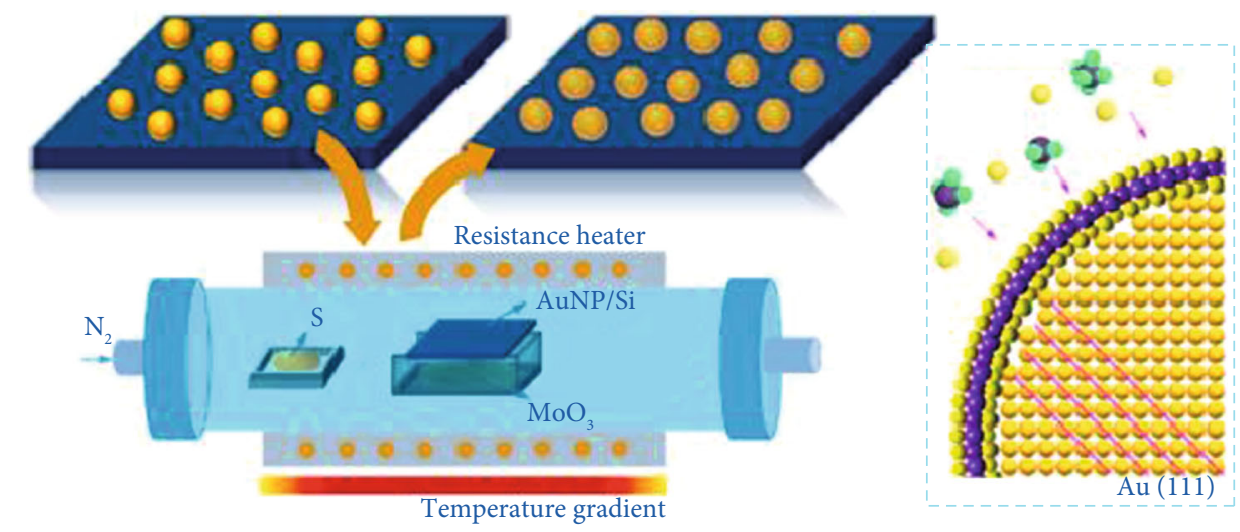

FIGURE 6: A schematic representation of CVD process of $\mathrm{MoS}_{2}$ shell growth on Au nanoparticles. Reproduced with permission from [29]. Copyright (C) 2020, American Chemical Society.

achieve this in two steps especially using rotary chemical vapor deposition (RCVP) [32]. This method has an excellent throwing power which enables the production of coatings of uniform thickness and properties with a low porosity [26, 27]. This method is also capable to offer localized, or selective deposition, on patterned substrates [27, 28]. CVD processes are employed in many thin film applications, such as dielectrics, conductors, passivation layers, oxidation barriers, conductive oxides, tribological and corrosion-resistant coatings, heat-resistant coatings, and epitaxial layers for microelectronics [27]. They are also used in the preparation of hightemperature materials (tungsten, ceramics, etc.) and the production of solar cells, high-temperature fiber composites, and particles of well-defined sizes [26, 27]. CVD techniques have been developed to produce $2 \mathrm{D}$ nanosheets, such as graphene [33], h-BN nanosheets [34], metal carbides [35], and borophenes [36] among others.

2.2.2. Sol-gel Nanofabrication. Sol-gel is a wet-chemical process that involves the formation of an inorganic colloidal suspension (sol) and gelation of the sol in a continuous liquid phase (gel) to form a three-dimensional network structure [37]. In sol-gel nanofabrication, a metal precursor in solution is deposited on suitable substrates and then heat treated to cause oxidation and/or sintering of the final products [17] as illustrated in Figure 7 [38]. It has been widely used for the fabrication of nanostructured functional metal oxide materials and alloys because it is cost effective and it offers the superiority of chemical reaction at molecular level, which is favorable to improve the chemical homogeneity of the final products [17, 39-42]. This process allows for the synthesis of pure and homogenous ceramic materials by means of preparation techniques different from the traditional process of fusion of oxides [43] which makes this method to stand out. By capping the particles with appropriate ligands, the dispersion can be stabilized in this liquid phase synthesis. For example, Moncada and coworkers reported the preparation of hybrid layered aluminosilicate nanoparticles (NPs) containing octadecyl amine (ODA) as the organic part and $\mathrm{SiO}_{2}$ NPs with spherical morphology containing ODA or without ODA by the sol-gel method and used for the formation of nanocomposites with polypropylene [43, 44].

2.2.3. Laser Pyrolysis Synthesis. Laser pyrolysis involves resonant energy transfer between laser photons and a gaseous species, reactant, or sensitizer [45]. This technique is commonly categorized as a vapor-phase synthesis process utilized for producing a nanomaterials (NMs) [43, 46]. In a typical 


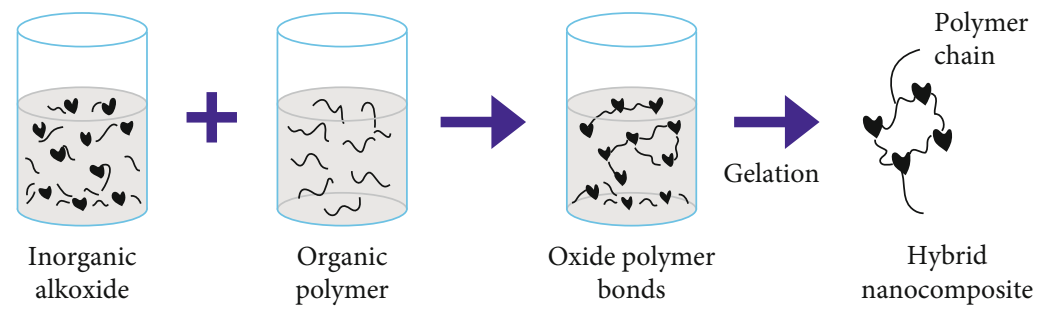

FIGURE 7: A schematic representation of sol-gel synthesis [38].

laser pyrolysis process, the gaseous-phase precursors are introduced to a chamber by a carrier gas (e.g., argon) where the gaseous-phase precursors meet the laser beam. The high-power laser beam (e.g., 2400 W) generates elevated localized temperatures which trigger the nucleation and growth of nanoparticles $[43,45]$. The nanoparticles are then collected by a catcher equipped with a filter.

2.2.4. Green Synthesis. Green synthesis uses reducing agents obtained from plant extracts to reduce aqueous species of the metal in solution. An example is the reduction of $\mathrm{Ag}^{+}$ from an aqueous solution of $\mathrm{AgNO}_{3}$ using plant extracts such as Clitoria ternatea, plants (green tea (Camellia sinensis), alfalfa (Medicago sativa), lemongrass (Cymbopogon flexuosus), and geranium (Pelargonium graveolens)) [47], Citrus paradisi (Grapefruit red) [48], and Solanum nigrum as reducing agents [49]. Other biological agents such as bacteria (Pseudomonas stutzeri AG259, Lactobacillus strains, etc.), fungi (Fusarium oxysporum, Aspergillus flavus), and algae (Lyngbya majuscula, Spirulina subsalsa, Rhizoclonium hieroglyphicum, and Chlorella vulgaris) may also be used as reducing agents for silver [47]. These agents present cost-effective and environmentally friendly pathways for nanoparticle synthesis. Silver nanoparticles, like magnesium oxide nanoparticles, exhibit antimicrobial properties [50]. The antimicrobial activity results from the interaction of silver ions with sulphuric groups in the cell membranes of bacteria and other microorganism [51]. Pure silver nanoparticles are characterized by high toxicity and low stability, an aspect that limits their antimicrobial activity and consequently their application in water purification systems. For this reason, synthesis of silver nanoparticles for water filtration is designed in such a way that they are stabilized through surface engineering, impregnated with other materials placed on substrates [52]. Some of the substrates that support silver nanoparticles include sand, zeolites [53], fiberglass [54], activated carbon [55], blotter paper [56], cellulose filters [57], ceramic filters [58], or polyurethane foams [59] among others. Materials used for impregnation of silver nanoparticles include polyamide-66 [60] and chitosan [48] among others. Some stabilizing agents are amine functionalized hydrosoluble silicone wax [60], chitosan, gelatin hydrogel [61], or dithiocarbamate ligands [62].

\section{Characterization of Nanostructures}

The most common characterization of nanostructures is in terms of shape and morphology and due to their exceedingly small size, dedicated tools and special techniques are usually required [1]. This information is usually obtained by various imaging techniques. For example, X-ray diffraction spectroscopy is usually used to give information on the crystalline structure of the nanostructured material synthesized and to determine the particle size. It therefore presents a suitable technique for studying size modulation of nanoparticles as a function of changes in dopants, temperature, and synthesis time among other parameters [63]. Further, changes in the crystallinity of synthesized nanostructures with changing degree of doping can be studied using Raman spectroscopy. This is inferred from changes in the vibration modes of the nanomaterial as a result of structural distortions (surface defects) caused by various dopant compositions. The changes may include signal resolution, broadening, or shifting [64]. Likewise, transmission electron microscopy (TEM) and scanning electron microscopy (SEM) can provide microstructural elucidation with varying dopant percentages and also give an estimate of the particle sizes [65]. Furthermore, both TEM and SEM can offer information on the level of aggregation or nonaggregation of the synthesized nanostructures. For instance, it is found that synthesized $\mathrm{MnFe}_{2} \mathrm{O}_{4}$ form aggregates but when coated with a Mn-Co oxide layer, the nanoparticles become nonaggregated [66].

$\mathrm{X}$-ray photoelectron spectroscopy (XPS) is another technique used in the characterization of nanostructures to provide their atomic composition. Since the properties of nanomaterials can significantly be modified by altering atomic composition of the core material or the dopant, the use of XPS can enable one to optimize the respective rations of each species in the nanomaterial. A further understanding of inner architectural properties of nanocomposites is important since they determine the amount of adsorption sites available. These can be inferred from the study of microporosity and specific surface areas using suitable adsorption isotherms such as the Langmuir adsorption isotherm, Freundlich adsorption models, or Brunauer-Dening-Dening-Teller $[63,65]$. To probe the interaction between nanostructures and bacteria, atomic force microscopy (AFM), transmission electron microscopy (TEM), and laser confocal microscopy (LCM) are used. This is confirmed by observing changes in the integrity of the cell membranes, resulting in the death of the bacteria. Inductively coupled plasma mass spectrometry (ICP-MS) may be used to quantify the concentration of silver ions leached from the nanocomposite matrix after a specified contact time with water samples containing the target microorganism [60]. Fourier transform infrared (FTIR) is also used to study the chemical interaction of various 
functional groups during synthesis and also to confirm successful surface modification of the nanocomposites [67].

\section{Application of Nanostructures in Sensors}

A sensor is a device which can detect variable quantities, usually electronically, and converts the measurement into specific signals $[68,69]$. The most important requirements of sensors are diversity, sensitivity, accuracy of information extracted, selectivity, and stability [68] which can enable us to monitor the environment around us and to use that information for different purposes [69]. There has been an increasing demand for the development of new sensor devices with specific characteristics such as improved sensitivity, low cost, faster response, reliability, rapider recovery, reduced size, in situ analysis, and simple operation [70] [71, 72]. Nanostructured materials have shown great potential in improving these properties for chemical and biological sensors [73]. Various nanostructured materials have been used in manufacturing nanosensors. For example, nanoscale wires (capability of high detection sensitivity), carbon nanotubes (very high surface area and high electron conductivity), thin films, metal and metal oxide nanoparticles, polymer, and biomaterials [74]. Since very many nanostructured materials have been used in sensors, in the next section, we provide an extensive review of the recent developments of metal, metal oxides, carbon nanotubes, and polymer nanostructured materials in sensors.

4.1. Metal Nanostructures in Sensors. Metal nanoparticles are known to have unique physical and chemical properties which make them extremely suitable for designing new and improved sensing devices especially electrochemical sensors and biosensors [75, 76]. Various metal nanoparticles such as gold $(\mathrm{Au})$, silver $(\mathrm{Ag})$, platinum $(\mathrm{Pt})$, palladium $(\mathrm{Pd})$, copper $(\mathrm{Cu})$, and cobalt $(\mathrm{Co})$, including rare earth metals, have been used in fabricating electrochemical sensors and biosensors, and they normally play different roles in diverse sensing systems [75]. The importance of these roles includes the immobilization of biomolecules, the catalysis of electrochemical reactions, and the enhancement of electron transfer between electrode surfaces and proteins, labeling biomolecules as well as acting as a reactant [75]. Metal nanoparticles can be used as analytical transducers in various sensing principles as well as signal amplification elements [77]. The combination of greatly resourceful nanoparticle sensing principles with recognition elements has resulted in bioassays with fast responses and visual outcome, appropriate for use in resource constrained environments [77]. For example, silver and gold nanoparticles have been used in the development of biosensors for point of care disease diagnosis [12].

The interparticle plasmon coupling of the nanoparticles leads to color changes which have been widely used in biosensors based on aggregation of the nanoparticles. For example, small gold nanoparticles are red and well dispersed but turn blue or purple on aggregation [78] while silver nanoparticles are yellowish brownish when dispersed but turn black when they aggregate [79]. The fundamental property of these nanoparticles has been used in the development of colori- metric sensor arrays with the potential of rapidity of analysis, which are cost effective and easy to use since they can provide naked eye observations [80]. A number of biosensors based on this predictable color changes such as biosensors for detection of $\alpha$-1-fetoprotein [81], antihepatitis B virus antibodies in human serum [82], breast cancer biomarkers [83], mycobacterial of the Mycobacterium tuberculosis complex [84], human immunodeficiency virus type 1 DNA [85], toxic metal pollutants [86], and organochlorine endosulfan pesticide (ESP) [87] as shown in Figure 8 have been developed.

Graphene sheets which were decorated with green synthesized gold nanoparticles have been reported for labelfree electrochemical impedance hybridization sensing of biomolecules such as HCG hormone in pregnant women due to their plasmon resonance [88-90]. By mixing $500 \mu \mathrm{l}$ of biosynthesized gold nanoparticle solution with the same volume of the test sample and testing the solution using a pregnancy test strip, the authors found that the gold nanoparticles changed color into pink when pregnancy was positive and gray when negative. They further claimed that the method was 100\% accurate for pregnancy diagnosis and can be used as an alternative method for a urine pregnancy test $[89,90]$.

Gold nanoparticles synthesized from patuletin isolated from Tagetes patula which was used as a capping and reducing agent as reported by Muhammad et al. were used as a chemosensor for piroxicam. In their work, they conjugated the gold nanoparticles with the patuletin, and the conjugate was found to be 63.2 by weight. They then examined the conjugate as a potential chemosensor with different drugs, but only one drug, piroxicam, was found to quench luminescence which followed Beer's law in a concentration range of $20-60 \mu \mathrm{M}$. The quenching was also found to be stable at different $\mathrm{pH}$, elevated temperatures, or addition of other drugs, and hence, they concluded that it could be important for molecular recognition applications [91].

Green synthesized silver nanoparticles from the aqueous solution of polysaccharide of guar gum (Cyamopsis tetragonoloba) plants displayed exceptional optical property towards ammonia with a very short response time of between 2 and 3 seconds and a detection limit of 1 ppm at room temperature $[92,93]$, and hence, this optical property towards ammonia at can be used as a sensor for the detection of ammonia level in biological fluids such as plasma, saliva, cerebrospinal liquid, and sweat $[92,93]$. Silver nanoparticles embedded in polymers have also been used in sensors as reported in a study by Kariuki and coworkers [94] where they embedded silver nanoparticles in poly (amic) acid (PAA) polymer matrix (PAA-Ag NPs) for the detection of nitrobenzene. They found that the PAA-Ag nanoparticles based sensor showed a detection limit of $1.68 \mathrm{mM}$ with a wide linear range of $10-600 \mathrm{mM}$ and a high sensitivity of $7.88 \mathrm{~mA} \mathrm{mM}^{-1}$ with low interference on structurally similar nitroaromatic compounds [94].

Silver nanoparticles can also enable sensing of various analytes by tagging them with the nanoparticles. In a study reported by Sepunaru et al. [95], silver nanoparticles were used to tag influenza virus which led to efficient electrochemical detection of the virus since the magnitude and frequency 


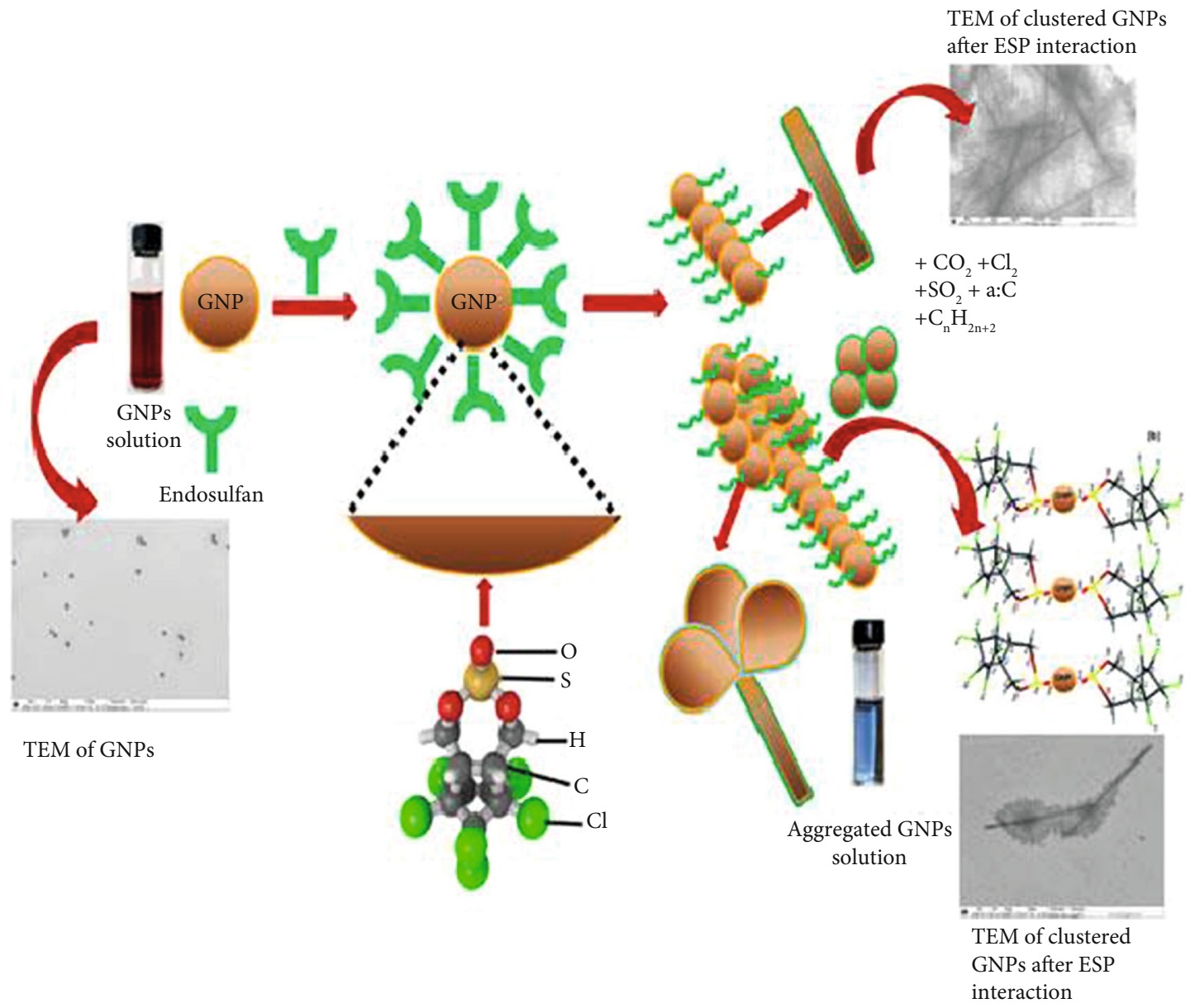

FIGURE 8: A diagram showing gold nanoparticles (GNPs) of $\sim 8 \mathrm{~nm}$ in diameter used for the detection of organochlorine endosulfan pesticide (ESP) as colorimetric sensor and the design of GNP-based chemical sensor for its quantitative estimation has also been proposed. The original wine red color of GNPs changes into various shades of blue after the addition of different concentrations of ESP solutions. A GNP-based sensing electrode has been used for designing of ESP detection chemical sensor at ambient temperature. Adapted with permission from [87]. Copyright (C) Materials Research Society 2018.

of the current increased linearly with the increasing virus concentration as well as the increasing surface coverage of the silver nanoparticles [95].

Platinum nanoparticles usually reveal good catalytic properties and have also been used in sensors or various analytes. For example, they have been used in sensors developed for the detection of hydrogen peroxide [96-99], cholesterol [100], mercury ions [101], and hydrogen [102].

Palladium nanoparticles are also characterized by their extensive catalytic properties and hence have found sensor applications towards gases, biomolecules, and hazardous toxic molecules [74]. Palladium nanoparticle-based materials are said to exhibit high electrocatalytic activity towards different target analytes. Palladium is also abundant over other noble metals such as platinum and gold, and this is making it a cheaper substitute for developing a number of electrochemical sensors [74]. Palladium in combination with other materials such as graphene forms nanocomposites which have been found to improve the mass diffusion of analytes. The nanocomposites normally offer electron tunneling which enables electron transfer between the active site and the elec- trode hence leading to effective electrochemical sensing performance [74]. A nanocomposite of $\mathrm{pd}$ and $\mathrm{pt}$ has been used to develop a sensor for nitrite $[103,104]$. Another study reported a nanocomposite of palladium nanoparticles with polypyrrole which was used to develop a sensor for the detection of nitrates [105], while another study reported a nanocomposite of palladium nanoparticle with polyvinylpyrrolidone to detect hydrogen peroxide [106].

Copper is also another metal which has fascinated many researchers as an ideal material for use in sensors since it has good stability, outstanding electrical conductivity, electrocatalytic properties, and low cost when compared with noble metal such as platinum, gold, and silver [74]. Copper-based nanostructured materials have very many exceptional properties which include high mass-transport rate, high surface to volume ratio, and the improved signal-to-noise ratio in electroanalytical measurements [74]. For example, copper nanoclusters prepared via a simple one-step electrodeposition process on platinum electrode were used to determine nitrates [107]. Also, cetyltrimethylammonium bromide(CTAB-) capped copper nanoparticles (CTAB-Cups) have 
been used as a colorimetric probe for the detection of dithiocarbamate pesticides [108]. Another study reports colorimetric copper-based sensors for the detection of mercury-(ii) ions [109].

4.2. Metal Oxide Nanostructures in Sensors. Semiconductor metal oxide-based nanostructured materials have been expansively used as sensors in numerous applications since they can enhance the sensor's performance due to their small crystallite size [110]. Semiconducting metal oxide- (SMOX-) based sensors are small, robust, inexpensive, and sensitive and easy to produce, making them highly attractive for handheld portable medical diagnostic detectors [110, 111]. They have been used to produce highly sensitive gas sensors mainly because of their good chemical reliability, real-time monitoring, and easy fabrication [112]. For example, a 3D nanoheterojunction layout of nickel oxide-zinc oxide (NiO$\mathrm{Zn})$ p-n semiconductors with a grain size of $\approx 20 \mathrm{~nm}$ nanometers and a porosity of $\approx 98 \%$ for the rapid room temperature chemical sensing of volatile organic compounds has been reported by Chen and coworkers [113]. In their work, they observed the sensor response was increased by more than four times, while the limit of detection was improved by decorating the $\mathrm{ZnO}$ nanoparticle networks with $\mathrm{NiO}$. Under solar light irradiation, the optimal NiO- $\mathrm{ZnO}$ nanoheterojunction networks demonstrated a strong and selective room temperature response to two important volatile organic compounds utilized for breath analysis. Likewise, $\mathrm{ZnO}$ /graphene oxide (GO) nanosheets, synthesized using the wetchemical method with an additional calcining treatment, for the tremendous sensing of acetone as a target gas have been reported [114]. The excellent sensing performance was ascribed to the synergistic effects between $\mathrm{ZnO}$ nanosheets and GO, which included a unique 2D structure, large specific surface area, suitable particle size, and abundant in-plane mesopores [114]. A ZnO/ $\mathrm{In}_{2} \mathrm{O}_{3}$ heterostructure-based sensor for ethanol gas at $240^{\circ} \mathrm{C}$ has been reported [115]. The sensor was found to exhibit a response as high as 170 toward $50 \mathrm{ppm}$ of ethanol, which is about 3.3 times higher than that of pure $\mathrm{In}_{2} \mathrm{O}_{3}$-based sensor as well as excellent selectivity, good longterm stability, and moderate response and recovery speed (35/46 s) toward ethanol [115].

Tungsten trioxide $\left(\mathrm{WO}_{3}\right)$, the second most commonly used semiconducting metal oxide in gas sensors, has been reported to show high sensor responses to several biomarkers found in breath, e.g., acetone, ammonia, carbon monoxide, hydrogen sulfide, toluene, and nitric oxide since the modern material science allows $\mathrm{WO}_{3}$ samples to be tailored to address certain sensing needs [111]. For example, Pt-functionalized $\mathrm{WO}_{3}$ hemitubes and graphene-functionalized $\mathrm{WO}_{3}$ hemitubes for the detection of acetone $\left(\mathrm{CH}_{3} \mathrm{COCH}_{3}\right)$ and hydrogen sulfide $\left(\mathrm{H}_{2} \mathrm{~S}\right)$ which are biomarkers for the diagnosis of diabetes and halitosis have been reported [116, 117]. Both studies reported remarkable selectivity, enhanced sensitivity, and low detection limits offering a potential platform for application in diabetes and halitosis diagnosis. These superior sensing properties were ascribed to the electronic sensitization of graphene and platinum-based materials by modulating space-charged layers at the interfaces between n-type $\mathrm{WO}_{3}$ hemitubes and p-type graphene-based materials, as identified by Kelvin Probe Force Microscopy (KPFM). The rapid response and superior sensitivity of the proposed sensing materials was found to follow cyclic thermal aging which demonstrated a good potential for real-time exhaled breath diagnosis of diseases [116, 117].

Graphene-functionalized tin oxide $\left(\mathrm{SnO}_{2}\right)$ nanofibers (NF)/nanosheets (NS) have also been reported in the detection of acetone and hydrogen sulfide levels in exhaled human breath as biomarkers for diabetes and halitosis [118] as well as for the detection of formaldehyde (HCHO) $[119,120]$. The sensors exhibited high sensitivity and low detection limits which was ascribed to the high specific area, suitable electron transfer channels, and the synergistic effect of the $\mathrm{SnO}_{2} \mathrm{NF} / \mathrm{NSs}$ and the graphene oxide network [118-120]. Another study reports a 3D hierarchical $\mathrm{In}_{2} \mathrm{O}_{3} @ \mathrm{SnO}_{2}$ coreshell nanofiber $\left(\mathrm{In}_{2} \mathrm{O}_{3} @ \mathrm{SnO}_{2}\right)$ designed using vertically aligned $\mathrm{SnO}_{2}$ nanosheets uniformly grown on the outside surface of $\mathrm{In}_{2} \mathrm{O}_{3}$ nanofibers and tested for the sensing performance of formaldehyde (HCHO) [121]. The sensing performance of the $\mathrm{In}_{2} \mathrm{O}_{3} @ \mathrm{SnO}_{2}$ nanocomposite was found to possess the highest response value, fast response/recovery speed, best selectivity, and lowest $\mathrm{HCHO}$ detection limit which were attributed to the synergistic effect of large specific surface areas of $\mathrm{SnO}_{2}$ nanosheet arrays, abundant adsorbed oxygen species on the surface, unique electron transformation between core-shell heterogeneous materials, and long electronic transmission channel of $\mathrm{SnO}_{2}$ transition layer [121].

Another study reports chromium (III) oxide nanoparticles coated with tin oxide nanofibers $\left(\mathrm{Cr}_{2} \mathrm{O}_{3}\right.$ NPs. coated $\mathrm{SnO}_{2}$ NFs.) synthesized using a sol-gel process and an electrospinning method and characterized by X-ray diffraction (XRD), scanning electron microscope (SEM), X-ray energy dispersive spectroscopy (EDS), and X-ray photoelectron spectroscopy (XPS) [112]. The Cr2O3 NPs. coated $\mathrm{SnO}_{2}$ NFs were found to exhibit low optimal operating temperature, high sensing response, excellent response-recovery time, and long-term stability to $\mathrm{C}_{2} \mathrm{H}_{2}$ [112].

All the examples described above clearly show that incorporating nanostructured materials into the sensors led to improved performances in terms of increased sensitivity, selectivity, stability, and detection limits.

4.3. Carbon Nanotubes in Sensors. Carbon nanotubes (CNTs) are theoretically cylindrical fabricated rolled up graphene sheets which can be classified single walled carbon nanotubes (SWCNTs) or multiwalled carbon nanotubes (MWCNTs) $[122,123]$. The SWCNTs normally consist of a single graphite sheet flawlessly wrapped into a cylindrical tube, while multiwalled carbon nanotube (MWCNTs) comprise an array of such nanotubes [124]. Although CNTs are made of carbon with similar dimension aspect ratio, they can be either metallic or semiconducting depending on the rolling up of the graphene layers [123]. They normally have a high aspect ratio which makes them suitable for functionalization through chemical or physical methods [123]. They can be produced via the chemical vapor deposition method which has the advantage to be scalable, to allow large-area deposition, and to provide CNTs that are already attached onto a substrate 
and hence easy to be collected [125]. They are said to have amazing electrical, mechanical, and thermal properties as well as partial antibacterial activity due to their high aspect ratio and high surface area [126]. The high sensitivity of the electronic properties of nanotubes to molecules adsorbed on their surface and the unparalleled unit surface providing for this high sensitivity make CNT a promising starting material for the development of super miniaturized chemical and biological sensors [127, 128]. The operation of the CNTbased sensors is established on the changes in the V-I curve of the nanotube as a result of adsorption of specific molecules on their surface [127] which is one of their most promising applications in electronics. The sensors should have a high sensitivity as well as fast response and recovery [127]. Carbon nanotubes have been used in gas sensors, biosensors, photosensors, and pressure sensors among others. In this section, we will provide a review of the current advances of carbon nanotubes in sensor application.

4.3.1. Carbon Nanotubes in Gas Sensors. Gas sensors are chemical sensors, which have found widespread applications in industry, environmental monitoring, space exploration, biomedicine, and pharmaceutics [129]. Highly sensitive and selective gas sensors are required to detect leakage of explosive gases such as hydrogen and also for real-time detections of lethal or pathogenic gases in industries [129]. Due to the increasing global warming, there is also a strong demand of sensitive and selective gas sensors which can monitor and control our ambient environment [129]. The most common gas sensing principle is said to be the adsorption and desorption of gas molecules on the sensing materials, and therefore, increasing the contact interfaces between analyte and the sensing material can significantly enhance the sensitivity of gas sensors [129]. The CNTs are known to possess a huge specific surface and a robust van der Waals binding energy, which can provide well-defined adsorption sites for gas molecules which enable the application of CNTs to be an adsorbent to remove some undesirable gases and a sensor to react with target gases reflected by self-changes of physiochemical properties $[129,130]$ as illustrated in Figure 9. Carbon nanotube-based gas sensors have been widely considered due to their prominent properties such as faster response, enhanced sensitivity, and lower operating temperature $[131,132]$.

The adsorption ability of the CNTs has been found to change through doping metal or nonmetals on the sidewalls [130]. When the dopant atom(s) are coupled with the carbon can cage, they constitute a mutual area which exerts a great influence on the adsorption behaviors of the as-produced CNTs for gas [130]. Sensing of gas molecules using the adsorption properties of CNTs doped with different metals such as Pt [134], Au [135], Pd [136], Ni [137], Al [138], and nonmetals such as B and N [139] has been reported. In a study reported by Zhang et al. [140] where they studied the gas-sensitive response of Pd-SWCNT sensors to five different kinds of $\mathrm{SF}_{6}$ decomposition gases $\left(\mathrm{SO}_{2} \mathrm{~F}_{2}, \mathrm{SOF}_{2}, \mathrm{SO}_{2}\right.$, $\mathrm{H}_{2} \mathrm{~S}$, and $\left.\mathrm{CF}_{4}\right)$, they found that the conductivity of the nanotube increases once exposed to adsorbed gases with $\mathrm{SO}_{2}$ having the highest conductivity while CF4 decreased

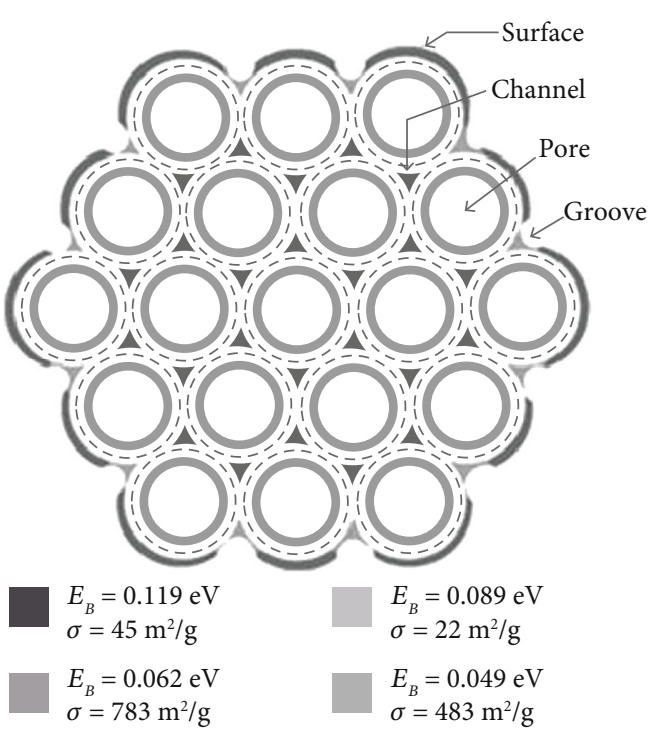

FIGURE 9: Schematic structure of a SWNT bundle showing the available sites for gas adsorption. Dashed line indicates the nuclear skeleton of the nanotubes. Adapted from [129], an open access article. Binding energies $E_{\mathrm{B}}$ and specific surface area contributions $(\sigma)$ for $\mathrm{H}_{2}$ adsorption on these sites are as indicated in [133].

[140]. An Au-CNT-based sensor has also been shown to selectively detect $\mathrm{H}_{2} \mathrm{~S}$ and $\mathrm{SO}_{2}$ as reported by Zhang et al. [141]. In their study, they found that Au-SWCNTs had better sensitivity than non-doped SWCNT in response to $\mathrm{H}_{2} \mathrm{~S}$ and $\mathrm{SO}_{2}$. They also found that the Au-SWCNT possessed a rewarding response to the two analytes where an increase in conductivity was realized in response to $\mathrm{SO}_{2}$ since there was a plentiful electron transfer to $\mathrm{SO}_{2}$ from the $\mathrm{Au}$ SWCNTs as opposed to a decline in tube conductivity for the case of $\mathrm{H}_{2} \mathrm{~S}$ where there was an electron shift from the $\mathrm{H}_{2} \mathrm{~S}$ to the SWCNTs. These results indicated that, based on the change of the nanotube conductivity, the Au-SWCNTbased sensors can selectively $\mathrm{SO}_{2}$ and $\mathrm{H}_{2} \mathrm{~S}$ gases.

Likewise, $\mathrm{NiCl}_{2}$-doped $\mathrm{MWCNT}$ sensors prepared by ultrasonic $\mathrm{NiCl}_{2} \cdot 6 \mathrm{H}_{2} \mathrm{O}$ crystal suspension liquid of carbon nanotubes when tested for the gas response of $\mathrm{SF}_{6}$ decomposition products have been reported [142], and the sensor was found to have a high sensitivity and fast response to $\mathrm{SO}_{2} \mathrm{~F}_{2}$ and $\mathrm{SOF}_{2}$, compared to $\mathrm{SO}_{2}$. Their results also indicated that MWCNTs modified by functional groups are sensitive to $\mathrm{H}_{2} \mathrm{~S}$, and MWCNTs modified by metal have a strong response to $\mathrm{SO}_{2} \mathrm{~F}_{2}$ confirming that the selectivity of CNTbased materials in detecting such gases can be achieved [142]. Other than doping the CNTs using metals, studies have also shown that modified CNTs using the hydroxyl and carboxyl functional groups have the potential to detect $\mathrm{H}_{2} \mathrm{~S}$ as well as $\mathrm{SO}_{2}[143,144]$.

Nitrogen dioxide $\left(\mathrm{NO}_{2}\right)$, a highly reactive gas and used mostly as a catalyst in oxidative reactions, for manufacturing explosives, as a polymerization inhibitor, and as rocket fuel, has been detected using SWCNTs and MWCNTs. SWCNTs functionalized with poly (m-aminobenzene sulfonic acid) have been reported to detect $\mathrm{NO}_{2}$ and ammonia $\mathrm{NH}_{3}$ gases at low concentrations with the lowest detected concentration 


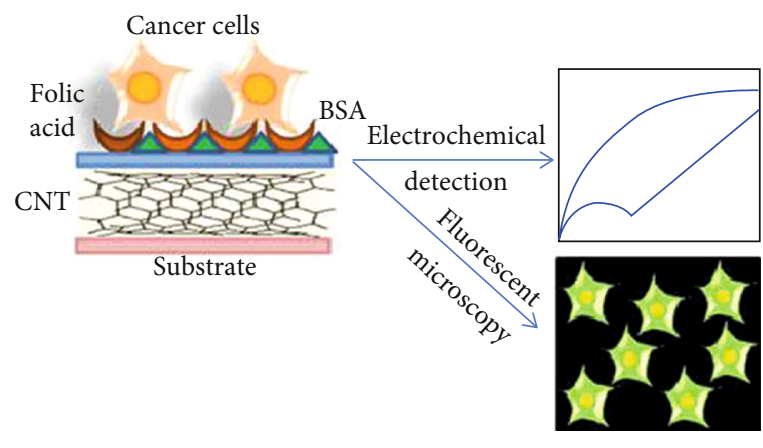

(a)

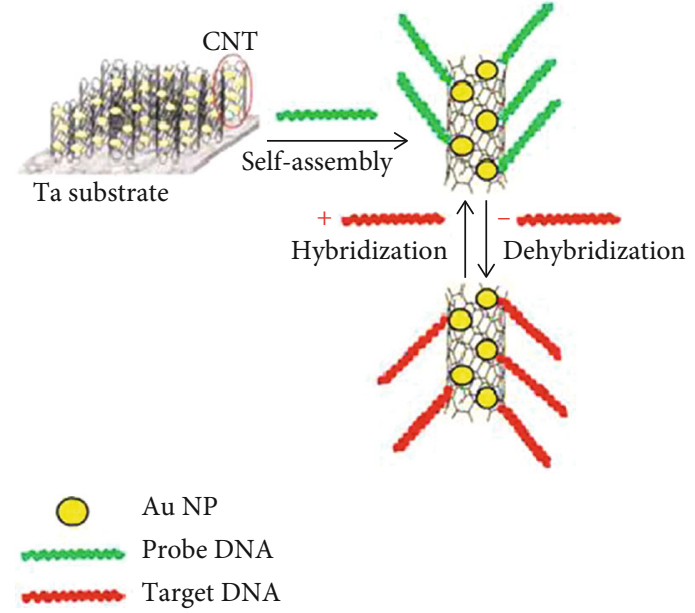

(b)

FIGURE 10: (a) Schematic illustration of carbon nanotubes immobilized on a sensor surface for an enhanced electrochemical detection of cancer cells. (b) Schematic representation of gold nanoparticles/aligned CNTs immobilized for an electrochemical DNA biosensor for cancer detection. Adapted from [163], an open access article.

for $\mathrm{NO}_{2}$ being $20 \mathrm{ppb}$ [145]. This was attributed to the functionalization of SWCNTs which was found to improve the processing capability and sensitivity of the sensors. Multiwalled carbon nanotubes (MCNTs) have also been used to develop NO2 gas sensors which are capable of measuring low concentration going down to $0.1 \mathrm{ppm}$ [146]. Another work has reported the detection of $\mathrm{NO}_{2}$ using a combination of SWCNTs and MWCNTs on porous silicon wafers which was done at different temperatures [147]. Their results indicated that the equal sensitivity for the two types of CNTs was achieved with higher temperatures for the SWCNTs as compared to the MWCNTs. A nanocomposite with MWCNTs using poly(thiophene-3-[2-(2-meth-oxyethoxy)ethoxy]-2,5diyl) (PThME) and 3-thiopheneacetate additive has also been reported to detect $\mathrm{NO}_{2}$ [148]. The detection range for $\mathrm{NO}$ and $\mathrm{NO}_{2}$ from this study was found to be between 2 and $5 \mathrm{ppm}$ while sensitivity in the response of these nanocomposite-based devices increased with the increase in temperature ranging between $25^{\circ} \mathrm{C}$ and $100^{\circ} \mathrm{C}$ [148].

Other gases which have been detected using carbon nanotubes include ammonia $\mathrm{NH}_{3}$ [149-152] gas, carbon monoxide (CO) gas [153-157], and chlorine gas [158-160] among others.

4.3.2. Carbon Nanotubes in Biosensors. A biosensor can be defined as a device that uses biochemical reactions to detect an analyte and a physiochemical component to produce a measurable signal [161]. It is normally composed of three components, the biological element or biomolecules, transducers, and detector as illustrated in Figure 10. The biological element is responsible for detecting the analyte and generating a response signal which is then transformed into a detectable response while the detector amplifies the processes and the signals before displaying it using a display system [162]. The biological elements are normally immobilized on the sensor surface, and their interaction with the analyte of interest generates a response signal which can be either an electrochemical signal, optical signal, or colorimetric signal.
The sensitivity and selectivity of the biosensors depend on the immobilization of the biological elements. Due to their unique properties described earlier, carbon nanotubes (CNTs) can serve as platforms for immobilization of biomolecules at their surface, combining their exceptional physical, chemical, electrical, and optical characteristics which make them one of the best suited materials for the transduction of signals associated with the recognition of analytes, metabolites, or disease biomarkers $[123,163,164]$ as illustrated in Figure 9 [163]. For example, CNTs have been used to develop electrochemical biosensors whose principle of action is based on oxidation and reduction reactions between the biomolecules and the analytes. Carbon nanotubes modified by redox polymers serving as a catalyst for the interaction of the biomolecules and the analyte have been reported [165]. The combination of CNTs with the polymers has been found to improve the electrical conductivity and mechanical strength of the hybrid material and hence the sensitivity of the biosensor [165]. Such combinations have been reported in biosensors for the detection of glucose, uric acid, hydrogen peroxide, ascorbic acid, dopamine, folic acid, cancer cells, and deoxyribonucleic acid (DNA) [163, 166-171].

Optical carbon nanotube-based biosensors have also been reported on the detection of cancer cells through changes in the emission of light (ultraviolet, visible, or infrared) $[172,173]$. In all the applications described above, the CNTs have been used to improve the immobilization of the biological elements which in turn led to an enhanced sensitivity, selectivity, and response time of the target analytes.

4.3.3. Carbon Nanotubes in Photo Sensors. A photo sensor can be defined as an electronic component that can detect the presence of visible light, infrared transmission, and/or ultraviolet (UV) energy [174]. They consist of semiconductors with photoconductivity in which electrical conductance can vary depending on the intensity of the radiation striking the material. They can be used for integrating natural and electrical lighting [175]. Due to their optical properties, 
TABLE 1: Sensors based on polymer nanocomposites.

\begin{tabular}{|c|c|c|c|}
\hline Polymer nanocomposite (sensory material) & Analyte & Detection limit & Reference \\
\hline Zinc oxide nanoparticles intercalated into polypyrrole ( $\mathrm{ZnO}-\mathrm{PPy})$ & Xanthine & $0.8 \mu \mathrm{M}$ & {$[196]$} \\
\hline Polypyrrole nanosheets decorated with platinum nanoparticles (PPy-Pt) & Hydrogen peroxide & $0.6 \mu \mathrm{M}$ & [197] \\
\hline $\mathrm{NiCo}_{2} \mathrm{O}_{4}$-polyaniline $\left(\mathrm{NiCo}_{2} \mathrm{O}_{4}\right.$-PANI $)$ & Glucose & $0.3833 \mu \mathrm{M}$ & {$[198]$} \\
\hline $\begin{array}{l}\text { Graphene polyaniline nanocomposite- (GR-PANI-) modified glassy } \\
\text { carbon electrode (GCE) (GR-PANI-GCE) }\end{array}$ & 4-Aminophenol & $6.5 \times 10^{-8} \mathrm{M}$ & [199] \\
\hline Graphene-polyaniline-horseradish peroxidase (Grp-PANI-HRP) & Malaria drug Artesunate & $0.012 \mathrm{ng} \mathrm{mL}^{-1}$ & [200] \\
\hline Polyaniline and zirconia nanocomposite film (PANI-ZrO2) & Esomeprazole & $97.21 \mathrm{ng} \mathrm{mL}^{-1}$ & {$[201]$} \\
\hline Gold-polyaniline-graphene nanocomposites (Au-Grp-PANI) & Nitrite & $0.01 \mu \mathrm{mol} \mathrm{L}-1$ & {$[202]$} \\
\hline Polypyrrole/graphene nanocomposite (PPy-Grp-GCE) & Adenine, guanine & $0.02 \mu \mathrm{M}$ and $0.01 \mu \mathrm{M}$ & {$[203]$} \\
\hline Polypyrrole/graphene oxide nanosheets (PPy-GrpO) & Dopamine & $73.3 \mathrm{nM}$ & {$[204]$} \\
\hline $\begin{array}{l}\text { Praphene-poly(3,4-ethylenedioxythiophene) (graphene-PEDOT) } \\
\text { nanocomposite film with ascorbate oxidase (AO) entrapped } \\
\text { (Grp-PEDOT-AO) }\end{array}$ & Ascorbic acid & $2.0 \mu \mathrm{M}$ & [205] \\
\hline Graphene-polyaniline- $\mathrm{Bi}_{2} \mathrm{O}_{3}\left(\mathrm{Grp}-\mathrm{PANI}-\mathrm{Bi}_{2} \mathrm{O}_{3}\right)$ composite & $\begin{array}{l}\text { Anti-inflammatory drug } \\
\text { Etodolac }\end{array}$ & $10.03 \mathrm{ng} \mathrm{mL}^{-1}$ & {$[206]$} \\
\hline $\begin{array}{l}\text { Copper phosphate nanospheres, polymerized dopamine } \\
\text { hydrochloride }\left(\mathrm{Cu}_{3}\left(\mathrm{PO}_{4}\right)_{2} / \mathrm{PDA} / \mathrm{Ab} 2 \mid \mathrm{GCE}\right)\end{array}$ & C-reactive protein & $0.13 \mathrm{pg} \mathrm{mL}^{-1}$ & {$[207]$} \\
\hline
\end{tabular}

CNTs have been used in photo sensors since when a high energy photon hits a semiconducting CNT, it generates an electron/hole pair within the nanostructure. A built-in potential then separates the two charge carriers enabling a photocurrent to be measured which is the concept behind CNT-based photo sensors [123].

A flexible CNTs photo sensor array for light detection has been reported [176]. In this study, the CNTs for light detection were embedded into a flexible parylene- $\mathrm{C}$ film and the photo sensor array fabricated using micromachining processes. Their results indicated an output photocurrent which varied linearly with the input light intensity [176]. A fabricated visible photo sensor based on the on double-walled carbon nanotube (DWCNT) film/ $\mathrm{Cu}_{2} \mathrm{O}$ nanoparticle (NP) film/ $/ \mathrm{TiO}_{2}$ nanotube array (TNA) heterojunctions has been reported [177]. Their results indicated an enhanced optoelectronic performance when compared to that of the heterojunctions without $\mathrm{Cu}_{2} \mathrm{O}$ nanoparticles. Carbon nanotubes can also be used to improve the selectivity of photo sensors. For example, perovskite/carbon nanotube hybrids were used to develop a photo sensor which could distinguish between ultraviolet, visible, and infrared spectrum [178]. In this study, the authors used organo-lead halide perovskites $\left(\mathrm{CH}_{3} \mathrm{NH}_{3} \mathrm{PbX}_{3}\right)$ which possess remarkable optoelectronic properties and tunable optical band gaps by changing the halogens and when integrated with SWCNTs can further improve their photoresponsivity [178]. The $\mathrm{CH}_{3} \mathrm{NH}_{3} \mathrm{PbCl}_{3}$-based photo sensor showed a responsivity up to $10^{5} \mathrm{~A} \mathrm{~W}^{-1}$ to ultraviolet and no obvious response to visible light, which is superior to that of most ultraviolet sensors [178] while the $\mathrm{CH}_{3} \mathrm{NH}_{3} \mathrm{PbBr}_{3}$-based photo sensor was found to exhibit a high responsivity to visible light [178], and therefore, by changing the halogen, the photo sensor is able to distinguish between the different electromagnetic radiations.

4.3.4. Carbon Nanotubes in Pressure Sensors. A pressure sensor is a device that can sense pressure and convert it into an electric signal where the amount depends upon the pressure applied [179]. Freestanding films containing vertically aligned CNTs are said to exhibit supercompressible foamlike behavior [180], whereas ultralong CNT blocks can act as pressure or strain sensors, exhibiting reversible electrical conductivities and a compressive strain response [181] and therefore can be used in pressure sensors. For example, a pressure sensor based on the arrangement of vertically aligned carbon nanotubes (VACNTs) which was supported by a polydimethylsiloxane (PDMS) matrix has been reported [182]. In this study, the VACNTs embedded in the PDMS matrix were structurally flexible and were able to provide a repeated sensing operation due to the high elasticities of both the polymer and the carbon nanotubes (CNTs) [182]. To accomplish flexible functional electronics, the VACNTbased pressure sensor was incorporated into a field-effect transistor, fabricated using sprayed semiconducting carbon nanotubes on plastic substrate [182]. In another study, functionalized carbon nanotubes on nonconductive fibers coated by electrophoretic deposition (EPD) onto a backing electrode followed by film formation onto the fibers creating a conductive network have been used to develop a pressure sensor [183]. The pressure sensor displayed a large in-plane change in electrical conductivity with applied out-of-plane pressure [183] indicating resilience of the nanocomposite interphase which enabled sensing of high pressures without permanent changes to the sensor response as well as showing high repeatability [183].

4.4. Polymer Nanocomposites in Sensors. Polymer nanocomposites comprise a class of materials formed by at least finely dispersed phase with nanomaterials such as nanoparticles, nanotubes, or nanosheets [184-186]. They are superior type of tools in which the nanomaterials are spread in a polymer matrix resulting in innovative materials with unique physical and chemical properties [184, 185, 187-193]. The polymer 
matrix can be made from a variety of polymers such as polyamides, polyethersulfone, polyurethanes, polyamic acid, poly(vinylidene fluoride) (PVDF), poly(vinyl alcohol) (PVA), polyacrylonitrile, or polytetrafluoroethylene (PTFE) among others $[184,194]$. Polymer nanocomposites (PNCs) have electrochemical properties and can be used as transducers in the development of electrochemical sensors and biosensors since they have high electrical conductivity rate, large surface area and fast electron rate leading to high sensitivity, and selectivity and low detection limits of the sensors [195]. In addition, the interactive fillers in the PNCs facilitate ion diffusion that impacts the sensing applications through intercalation into the PNC matrices leading to better stability of active electron transfer sites and detection limits [195]. These active fillers help in reducing the layer thickness in PNC leading to ultrathin electrochemical detector technology [195]. Based on these properties of PNC, they have been used in the development of sensors for various analytes some of which are summarized in Table 1.

\section{Conclusions and Future Perspectives}

In this review article, we have discussed fabrication techniques of different nanostructures as well as their applications of in the field of sensors. Owing to their superior physicochemical and plasmonic properties of nanostructured materials, they have generated a great deal of interest in many sensing applications. Though the potential uses of these nanostructures in sensors applications are numerous, there are a few limitations which might hinder these applications. For example, gas sensors based on carbon nanotubes have been found to lack selectivity [123]. This lack of selectivity is a major roadblock which can hamper further usage of these CNT-based devices; though this can be mitigated by coupling of the CNTs with other materials, more work needs to be done to improve their selectivity. There are also technical difficulties of nanostructure fabrication as well as serious concerns about nanostructure toxicity which might vary depending on the physical characteristics of each new particle type. Further research is therefore required to evaluate and solve these issues. The sustainability of the nanostructured materials which is very important has not been fully investigated, and therefore, it would be important to look into their sustainability in sensor applications. If the issues can be overcome, the high sensitivity, specificity, reduced cost, portability, and reusability of nanostructures which has been described in this review will make nanostructured materials an appealing alternative to current sensors. This is however achievable since there has been a continued progress in the field of nanotechnology with increasing research in the nanoscale which can lead to enhanced performance of the existing sensors as well as the development of newer sensors based on novel mechanisms.

\section{Data Availability}

The data used to support the findings are cited within the article as figures.

\section{Conflicts of Interest}

The author declares that there are no conflicts of interest regarding the publication of this review.

\section{Acknowledgments}

The author would like to thank the School of Pharmacy and Health Sciences, United States International UniversityAfrica, for providing a conducive environment and facilities from which this work was written.

\section{References}

[1] X. Cheng, 10 - Nanostructures: fabrication and applications, in Nanolithography, M. Feldman, Ed., Woodhead Publishing, 2014

[2] W. G. Kreyling, M. Semmler-Behnke, and Q. Chaudhry, "A complementary definition of nanomaterial," Nano Today, vol. 5, no. 3, pp. 165-168, 2010.

[3] M. M. Bellah, S. M. Christensen, and S. M. Iqbal, "Nanostructures for medical diagnostics," Journal of Nanomaterials, vol. 2012, Article ID 486301, 21 pages, 2012.

[4] M. Nasrollahzadeh, Z. Issaabadi, M. Sajjadi, S. M. Sajadi, and M. Atarod, "Types of Nanostructures," in Interface Science and Technology, pp. 29-80, Elsevier, 2019.

[5] N. Nasiri and C. Clarke, "Nanostructured gas sensors for medical and health applications: low to high dimensional materials," Biosensors, vol. 9, no. 1, p. 43, 2019.

[6] X. Huang, I. H. el-Sayed, W. Qian, and M. A. el-Sayed, "Cancer cell imaging and photothermal therapy in the nearinfrared region by using gold nanorods," Journal of the American Chemical Society, vol. 128, no. 6, pp. 2115-2120, 2006.

[7] P. K. Jain and M. A. El-Sayed, "Universal scaling of plasmon coupling in metal nanostructures: extension from particle pairs to nanoshells," Nano Letters, vol. 7, no. 9, pp. 28542858, 2007.

[8] P. K. Jain, X. Huang, I. H. el-Sayed, and M. A. el-Sayed, "Noble metals on the nanoscale: optical and photothermal properties and some applications in imaging, sensing, biology, and medicine," Accounts of Chemical Research, vol. 41, no. 12, pp. 1578-1586, 2008.

[9] P. Logeswari, S. Silambarasan, and J. Abraham, "Ecofriendly synthesis of silver nanoparticles from commercially available plant powders and their antibacterial properties," Scientia Iranica, vol. 20, no. 3, pp. 1049-1054, 2013.

[10] V. V. Makarov, A. J. Love, O. V. Sinitsyna et al., “"Green” nanotechnologies: synthesis of metal nanoparticles using plants," Acta Naturae, vol. 6, no. 1, pp. 35-44, 2014.

[11] A. Verma and M. S. Mehata, "Controllable synthesis of silver nanoparticles using Neem leaves and their antimicrobial activity," Journal of Radiation Research and Applied Sciences, vol. 9, no. 1, pp. 109-115, 2019.

[12] N. Noah, Green synthesis: characterization and applications of silver and gold nanoparticles, in Green Synthesis, Characterization and Applications of Nanoparticles, S. Holt, Ed., Elsevier Publishers, 2018.

[13] M. Muhammed, "Engineering of nanostructured materials," in In Nanostructures: Synthesis, Functional Properties and Applications. NATO Science Series (Series II: Mathematics, 
Physics and Chemistry), Springer Netherlands, Dordrecht, 2003.

[14] H.-D. Yu, M. D. Regulacio, E. Ye, and M. Y. Han, "Chemical routes to top-down nanofabrication," Chemical Society Reviews, vol. 42, no. 14, pp. 6006-6018, 2013.

[15] E. Stern, J. F. Klemic, D. A. Routenberg et al., "Label-free immunodetection with CMOS-compatible semiconducting nanowires," Nature, vol. 445, no. 7127, pp. 519-522, 2007.

[16] B. M. Venkatesan and R. Bashir, "Nanopore sensors for nucleic acid analysis," Nature Nanotechnology, vol. 6, no. 10, pp. 615-624, 2011.

[17] A. Biswas, I. S. Bayer, A. S. Biris, T. Wang, E. Dervishi, and F. Faupel, "Advances in top-down and bottom-up surface nanofabrication: Techniques, applications \& future prospects," Advances in Colloid and Interface Science, vol. 170, no. 1-2, pp. 2-27, 2012.

[18] J. E. E. Baglin, "Ion beam nanoscale fabrication and lithography-a review," Applied Surface Science, vol. 258, no. 9, pp. 4103-4111, 2012.

[19] S. Kawata, H. B. Sun, T. Tanaka, and K. Takada, "Finer features for functional microdevices," Nature, vol. 412, no. 6848, pp. 697-698, 2001.

[20] Y. Qiao, D. Wang, and J. M. Buriak, "Block copolymer templated etching on silicon," Nano Letters, vol. 7, no. 2, pp. 464-469, 2007.

[21] B. Fabre, L. Hennous, S. Ababou-Girard, and C. Meriadec, "Electroless patterned assembly of metal nanoparticles on hydrogen-terminated silicon surfaces for applications in photoelectrocatalysis," ACS Applied Materials \& Interfaces, vol. 5, no. 2, pp. 338-343, 2012.

[22] H. Yu, D. Wang, and M.-Y. Han, "Top-down solid-phase fabrication of nanoporous cadmium oxide architectures," Journal of the American Chemical Society, vol. 129, no. 8, pp. 2333-2337, 2007.

[23] T. Prasad Yadav, R. Manohar Yadav, and D. Pratap Singh, "Mechanical milling: a top down approach for the synthesis of nanomaterials and nanocomposites," Nanoscience and Nanotechnology, vol. 2, no. 3, pp. 22-48, 2012.

[24] S. Bashir and J. Liu, "Chapter 2 - Overviews of synthesis of nanomaterials," in Advanced Nanomaterials and their Applications in Renewable Energy, J. L. Liu and S. Bashir, Eds., pp. 51-115, Elsevier, Amsterdam, 2015.

[25] E. Valentin, S. Auvray, A. Filoramo et al., "Self-assembly fabrication of high performance carbon nanotubes based FETs," MRS Proceedings, vol. 772, 2003.

[26] S. Rauf, A. Glidle, and J. M. Cooper, "Production of quantum dot barcodes using biological self-assembly," Advanced Materials, vol. 21, no. 40, pp. 4020-4024, 2009.

[27] J.-O. Carlsson and P. M. Martin, "Chapter 7 - Chemical vapor deposition," in Handbook of Deposition Technologies for Films and Coatings (Third Edition), P. M. Martin, Ed., pp. 314-363, William Andrew Publishing, Boston, 2010.

[28] Y. B. Pottathara, Y. Grohens, V. Kokol, N. Kalarikkal, and S. Thomas, "Chapter 1 - Synthesis and Processing of Emerging Two-Dimensional Nanomaterials," in Nanomaterials Synthesis, pp. 1-25, Elsevier, 2019.

[29] Y. Li, J. D. Cain, E. D. Hanson et al., “Au@MoS2core-shell heterostructures with strong light-matter interactions," Nano Letters, vol. 16, no. 12, pp. 7696-7702, 2016.

[30] R. Binions and I. P. Parkin, "Novel Chemical Vapour Deposition Routes to Nanocomposite Thin Films," in Advances in Nanocomposites - Synthesis, Characterization and Industrial Applications, United Kingdom, 2011.

[31] F. Ogawa, C. Masuda, and H. Fujii, "In situ chemical vapor deposition of metals on vapor-grown carbon fibers and fabrication of aluminum-matrix composites reinforced by coated fibers," Journal of Materials Science, vol. 53, no. 7, pp. 5036-5050, 2018.

[32] J. Zhang and T. Goto, "Fabrication of $\mathrm{Al}_{2} \mathrm{O}_{3}-\mathrm{Cu}$ Nanocomposites Using Rotary Chemical Vapor Deposition and Spark Plasma Sintering," Journal of Nanomaterials, vol. 2015, Article ID 790361, 7 pages, 2015.

[33] P. R. Somani, S. P. Somani, and M. Umeno, "Planer nanographenes from camphor by CVD," Chemical Physics Letters, vol. 430, no. 1-3, pp. 56-59, 2006.

[34] Y. Shi, C. Hamsen, X. Jia et al., "Synthesis of few-layer hexagonal boron nitride thin film by chemical vapor deposition," Nano Letters, vol. 10, no. 10, pp. 4134-4139, 2010.

[35] Y. Gogotsi, "Transition metal carbides go 2D," Nature Materials, vol. 14, no. 11, pp. 1079-1080, 2015.

[36] G. Tai, T. Hu, Y. Zhou et al., "Synthesis of atomically thin boron films on copper foils," Angewandte Chemie, vol. 54, no. 51, pp. 15473-15477, 2015.

[37] R. Asmatulu, "Nanocoatings for corrosion protection of aerospace alloys," in Corrosion Protection and Control Using Nanomaterials, V. S. Saji and R. Cook, Eds., pp. 357-374, Woodhead Publishing, 2012.

[38] M. Oliveira and A. Machado, Preparation of polymer-based nanocomposites by different routes, a book chapter in Nanocomposites: Synthesis, Characterization and Applications Book, X. Wang, Ed., NOVA Publishers, 2013.

[39] Y. Lu, W. Dong, J. Ding, W. Wang, and A. Wang, "Hydroxyapatite nanomaterials: synthesis, properties, and functional applications," in Nanomaterials from Clay Minerals, A. Wang and W. Wang, Eds., pp. 485-536, Elsevier, 2019.

[40] S. K. Padmanabhan, A. Balakrishnan, M. C. Chu, Y. J. Lee, T. N. Kim, and S. J. Cho, "Sol-gel synthesis and characterization of hydroxyapatite nanorods," Particuology, vol. 7, no. 6, pp. 466-470, 2009.

[41] C. Daraio and S. Jin, "Synthesis and patterning methods for nanostructures useful for biological applications," in Nanotechnology for Biology and Medicine: At the Building Block Level, G. A. Silva and V. Parpura, Eds., pp. 27-44, Springer New York, New York, NY, 2012.

[42] V. de Oliveira Sousa Neto, T. M. Freire, G. D. Saraiva et al., "Chapter 5 - Water Treatment Devices Based on Zero-Valent Metal and Metal Oxide Nanomaterials," in Nanomaterials Applications for Environmental Matrices, pp. 187-225, Elsevier, 2019.

[43] S. Prasad, V. Kumar, S. Kirubanandam, and A. Barhoum, "Chapter 11 - Engineered nanomaterials: nanofabrication and surface functionalization," in Emerging Applications of Nanoparticles and Architecture Nanostructures, A. Barhoum and A. S. H. Makhlouf, Eds., pp. 305-340, Elsevier, 2018.

[44] E. Moncada, R. Quijada, and J. Retuert, "Nanoparticles prepared by the sol-gel method and their use in the formation of nanocomposites with polypropylene," Nanotechnology, vol. 18, no. 33, p. 335606, 2007.

[45] S. Wang and L. Gao, "Chapter 7 - Laser-driven nanomaterials and laser-enabled nanofabrication for industrial applications," in Industrial Applications of Nanomaterials, S. Thomas, Y. Grohens, and Y. B. Pottathara, Eds., pp. 181-203, Elsevier, 2019. 
[46] D. Sumanth Kumar, B. J. Kumar, and H. M. Mahesh, "Chapter 3 - Quantum nanostructures (QDs): an overview," in Synthesis of Inorganic Nanomaterials, S. M. Bhagyaraj, Ed., pp. 59-88, Woodhead Publishing, 2018.

[47] A. Rus, V.-D. Leordean, and P. Berce, "Silver nanoparticles (AgNP) impregnated filters in drinking water disinfection," MATEC Web of Conferences, vol. 137, article 07007, 2017.

[48] W. B. Ayinde, W. M. Gitari, M. Munkombwe, A. Samie, and J. A. Smith, "Green synthesis of AgMgOnHaP nanoparticles supported on chitosan matrix: defluoridation and antibacterial effects in groundwater," Journal of Environmental Chemical Engineering, vol. 8, no. 5, article 104026, 2020.

[49] N. Krithiga, A. Rajalakshmi, and A. Jayachitra, "Green synthesis of silver nanoparticles using leaf extracts ofClitoria ternateaandSolanum nigrumand study of its antibacterial effect against common nosocomial pathogens," Journal of Nanoscience, vol. 2015, Article ID 928204, 8 pages, 2015.

[50] H. Alizadeh, M. Salouti, and R. Shapouri, "Bactericidal effect of silver nanoparticles on intramacrophage Brucella abortus 544," Jundishapur J Microbiol, vol. 7, no. 3, article e9039, 2014.

[51] N. Durán, M. Durán, M. B. de Jesus, A. B. Seabra, W. J. Fávaro, and G. Nakazato, "Silver nanoparticles: a new view on mechanistic aspects on antimicrobial activity," Nanomedicine: Nanotechnology, Biology and Medicine, vol. 12, no. 3, pp. 789-799, 2016.

[52] S. Mohanty, S. Mishra, P. Jena, B. Jacob, B. Sarkar, and A. Sonawane, "An investigation on the antibacterial, cytotoxic, and antibiofilm efficacy of starch-stabilized silver nanoparticles," Nanomedicine: Nanotechnology, Biology and Medicine, vol. 8, no. 6, pp. 916-924, 2012.

[53] Y. Matsumura, K. Yoshikata, S. I. Kunisaki, and T. Tsuchido, "Mode of bactericidal action of silver zeolite and its comparison with that of silver nitrate," Applied and Environmental Microbiology, vol. 69, no. 7, pp. 4278-4281, 2003.

[54] G. Nangmenyi, Z. Yue, S. Mehrabi, E. Mintz, and J. Economy, "Synthesis and characterization of silver-nanoparticleimpregnated fiberglass and utility in water disinfection," Nanotechnology, vol. 20, no. 49, article 495705, 2009.

[55] A. H. M. El-Aassar, M. M. Said, A. M. Abdel-Gawad, and H. A. Shawky, "Using silver nanoparticles coated on activated carbon granules in columns for microbiological pollutants water disinfection in Abu Rawash area, Great Cairo, Egypt," Australian Journal of Basic and Applied Sciences, vol. 7, no. 1, pp. 422-432, 2013.

[56] T. A. Dankovich and D. G. Gray, "Bactericidal paper impregnated with silver nanoparticles for point-of-use water treatment," Environmental Science \& Technology, vol. 45, no. 5, pp. 1992-1998, 2011.

[57] S. M. Praveena, L. S. Han, L. T. L. Than, and A. Z. Aris, "Preparation and characterisation of silver nanoparticle coated on cellulose paper: evaluation of their potential as antibacterial water filter," Journal of Experimental Nanoscience, vol. 11, no. 17, pp. 1307-1319, 2016.

[58] E. N. Kallman, V. A. Oyanedel-Craver, and J. A. Smith, "Ceramic filters impregnated with silver nanoparticles for point-of-use water treatment in rural Guatemala," Journal of Environmental Engineering, vol. 137, no. 6, pp. 407-415, 2011.

[59] P. Jain and T. Pradeep, "Potential of silver nanoparticlecoated polyurethane foam as an antibacterial water filter,"
Biotechnology and Bioengineering, vol. 90, no. 1, pp. 59-63, 2005.

[60] L. A. D. Koslowski, A. L. Nogueira, S. Licodiedoff, A. T. Comper, and M. V. Folgueras, "Silver nanoparticles impregnated with polyamide-66 to disinfect drinking water," Ambiente e Agua - An Interdisciplinary Journal of Applied Science, vol. 13, no. 6, 2018.

[61] N. T.-P. Nguyen, L. V. H. Nguyen, N. T. Thanh et al., "Stabilization of silver nanoparticles in chitosan and gelatin hydrogel and its applications," Materials Letters, vol. 248, pp. 241$245,2019$.

[62] P. J. Reynoso-García, M. Güizado-Rodríguez, V. Barba, G. Ramos-Ortiz, and H. Martínez-Gutiérrez, "Stabilization of silver nanoparticles with a dithiocarbamate ligand and formation of nanocomposites by combination with polythiophene derivative nanoparticles," Advances in Condensed Matter Physics, vol. 2018, Article ID 4376051, 9 pages, 2018.

[63] B. Chouchene, T. B. Chaabane, K. Mozet et al., "Porous Aldoped $\mathrm{ZnO}$ rods with selective adsorption properties," Applied Surface Science, vol. 409, pp. 102-110, 2017.

[64] R. Vinodkumar, I. Navas, S. R. Chalana et al., "Highly conductive and transparent laser ablated nanostructured $\mathrm{Al}$ : ZnO thin films," Applied Surface Science, vol. 257, no. 3, pp. 708-716, 2010.

[65] H. A. Sani, M. B. Ahmad, M. Z. Hussein, N. A. Ibrahim, A. Musa, and T. A. Saleh, "Nanocomposite of $\mathrm{ZnO}$ with montmorillonite for removal of lead and copper ions from aqueous solutions," Process Safety and Environmental Protection, vol. 109, pp. 97-105, 2017.

[66] Z. Ma, D. Zhao, Y. Chang, S. Xing, Y. Wu, and Y. Gao, "Synthesis of MnFe2O4@Mn-Co oxide core-shell nanoparticles and their excellent performance for heavy metal removal," Dalton Transactions, vol. 42, no. 39, pp. 14261-14267, 2013.

[67] M. Kokate, K. Garadkar, and A. Gole, "One pot synthesis of magnetite-silica nanocomposites: applications as tags, entrapment matrix and in water purification," Journal of Materials Chemistry A, vol. 1, no. 6, pp. 2022-2029, 2013.

[68] A. J. S. Ahammad, J.-J. Lee, and M. A. Rahman, "Electrochemical sensors based on carbon nanotubes," Sensors, vol. 9, no. 4, pp. 2289-2319, 2009.

[69] A. I. Ayesh, "Metal/metal-oxide nanoclusters for gas sensor applications," Journal of Nanomaterials, vol. 2016, Article ID 2359019, 17 pages, 2016.

[70] S. Su, W. Wu, J. Gao, J. Lu, and C. Fan, "Nanomaterials-based sensors for applications in environmental monitoring," Journal of Materials Chemistry, vol. 22, no. 35, pp. 18101-18110, 2012.

[71] V. D. N. Bezzon, T. L. A. Montanheiro, B. R. C. de Menezes et al., "Carbon nanostructure-based sensors: a brief review on recent advances," Advances in Materials Science and Engineering, vol. 2019, Article ID 4293073, 21 pages, 2019.

[72] S. Mehdi Aghaei, M. M. Monshi, I. Torres, S. M. J. Zeidi, and I. Calizo, "DFT study of adsorption behavior of NO, CO, $\mathrm{NO} 2$, and $\mathrm{NH} 3$ molecules on graphene-like BC3: a search for highly sensitive molecular sensor," Applied Surface Science, vol. 427, pp. 326-333, 2018.

[73] Y. P. Zhao, S. . H. Li, S. B. Chaney et al., "Designing nanostructures for sensor applications," Journal of Electronic Materials, vol. 35, no. 5, pp. 846-851, 2006.

[74] R. Abdel-Karim, Y. Reda, and A. Abdel-Fattah, "Review-nanostructured materials-based nanosensors," Journal of the Electrochemical Society, vol. 167, no. 3, article 037554, 2020. 
[75] X. Luo, A. Morrin, A. . J. Killard, and M. . R. Smyth, "Application of nanoparticles in electrochemical sensors and biosensors," Electroanalysis, vol. 18, no. 4, pp. 319-326, 2006.

[76] G. Maduraiveeran and W. Jin, "Nanomaterials based electrochemical sensor and biosensor platforms for environmental applications," Trends in Environmental Analytical Chemistry, vol. 13, pp. 10-23, 2017.

[77] R. M. Pallares, N. T. K. Thanh, and X. Su, "Sensing of circulating cancer biomarkers with metal nanoparticles," Nanoscale, vol. 11, no. 46, pp. 22152-22171, 2019.

[78] M. Lin, H. Pei, F. Yang, C. Fan, and X. Zuo, "Applications of gold nanoparticles in the detection and identification of infectious diseases and biothreats," Advanced Materials, vol. 25, no. 25, pp. 3490-3496, 2013.

[79] G. Doria, J. Conde, B. Veigas et al., "Noble metal nanoparticles for biosensing applications," Sensors, vol. 12, no. 2, pp. 1657-1687, 2012.

[80] J. Sun, Y. Lu, L. He, J. Pang, F. Yang, and Y. Liu, "Colorimetric sensor array based on gold nanoparticles: design principles and recent advances," TrAC Trends in Analytical Chemistry, vol. 122, p. 115754, 2020.

[81] X. Che, R. Yuan, Y. Chai, J. Li, Z. Song, and J. Wang, "Amperometric immunosensor for the determination of $\alpha$-1-fetoprotein based on multiwalled carbon nanotube-silver nanoparticle composite," Journal of Colloid and Interface Science, vol. 345, no. 2, pp. 174-180, 2010.

[82] A. de la Escosura-Muñiz, M. Maltez-da Costa, C. SánchezEspinel et al., "Gold nanoparticle-based electrochemical magnetoimmunosensor for rapid detection of anti-hepatitis B virus antibodies in human serum," Biosensors and Bioelectronics, vol. 26, no. 4, pp. 1710-1714, 2010.

[83] A. Ambrosi, F. Airò, and A. Merkoçi, "Enhanced gold nanoparticle based ELISA for a breast cancer biomarker," Analytical Chemistry, vol. 82, no. 3, pp. 1151-1156, 2010.

[84] P. Costa, A. Amaro, A. Botelho, J. Inácio, and P. V. Baptista, "Gold nanoprobe assay for the identification of mycobacteria of the Mycobacterium tuberculosis complex," Clinical Microbiology and Infection, vol. 16, no. 9, pp. 1464-1469, 2010.

[85] M. B. Wabuyele and T. Vo-Dinh, "Detection of human immunodeficiency virus type 1 DNA sequence using plasmonics nanoprobes," Analytical Chemistry, vol. 77, no. 23, pp. 7810-7815, 2005.

[86] E. Priyadarshini and N. Pradhan, "Gold nanoparticles as efficient sensors in colorimetric detection of toxic metal ions: a review," Sensors and Actuators B: Chemical, vol. 238, pp. 888-902, 2017.

[87] P. Goel and M. Arora, "Fabrication of chemical sensor for organochlorine pesticide detection using colloidal gold nanoparticles," MRS Communications, vol. 8, no. 3, pp. 1000$1007,2018$.

[88] Y. Hu, S. Hua, F. Li et al., "Green-synthesized gold nanoparticles decorated graphene sheets for label-free electrochemical impedance DNA hybridization biosensing," Biosensors and Bioelectronics, vol. 26, no. 11, pp. 4355-4361, 2011.

[89] T. S. Santra, F.-G. Tseng, and T. K. Barik, "Green biosynthesis of gold nanoparticles and biomedical applications," Journal of Nano Research and Application, vol. 2, no. 6-2, pp. 5-12, 2014.

[90] P. Kuppusamy, M. Y. Mashitah, G. P. Maniam, and N. Govindan, "Biosynthesized gold nanoparticle developed as a tool for detection of HCG hormone in pregnant women urine sample," Asian Pacific Journal of Tropical Disease, vol. 4, no. 3, p. 237, 2014.

[91] M. Ateeq, M. R. Shah, N. . Ain et al., "Green synthesis and molecular recognition ability of patuletin coated gold nanoparticles," Biosensors and Bioelectronics, vol. 63, pp. 499505, 2015.

[92] S. Pandey, G. K. Goswami, and K. K. Nanda, "Green synthesis of biopolymer-silver nanoparticle nanocomposite: an optical sensor for ammonia detection," International Journal of Biological Macromolecules, vol. 51, no. 4, pp. 583-589, 2012.

[93] R. Kotcherlakota, S. Das, and C. R. Patra, "Therapeutic applications of green-synthesized silver nanoparticles," in Green Synthesis, Characterization and Applications of Nanoparticles, S. I. A. Shukla, Ed., pp. 389-428, Elsevier, 2018.

[94] V. M. Kariuki, S. A. Fasih-Ahmad, F. J. Osonga, and O. A. Sadik, "An electrochemical sensor for nitrobenzene using $\pi$ conjugated polymer-embedded nanosilver," Analyst, vol. 141, no. 7, pp. 2259-2269, 2016.

[95] L. Sepunaru, B. J. Plowman, S. V. Sokolov, N. P. Young, and R. G. Compton, "Rapid electrochemical detection of single influenza viruses tagged with silver nanoparticles," Chemical Science, vol. 7, no. 6, pp. 3892-3899, 2016.

[96] S. Palanisamy, H. F. Lee, S. M. Chen, and B. Thirumalraj, “An electrochemical facile fabrication of platinum nanoparticle decorated reduced graphene oxide; application for enhanced electrochemical sensing of $\mathrm{H} 2 \mathrm{O} 2$," RSC Advances, vol. 5, no. 128, pp. 105567-105573, 2015.

[97] R. Jiménez-Pérez, J. González-Rodríguez, M. I. GonzálezSánchez, B. Gómez-Monedero, and E. Valero, "Highly sensitive $\mathrm{H} 2 \mathrm{O} 2$ sensor based on poly(azure A)-platinum nanoparticles deposited on activated screen printed carbon electrodes," Sensors and Actuators B: Chemical, vol. 298, article 126878, 2019.

[98] G. Yin, L. Xing, X. J. Ma, and J. Wan, "Non-enzymatic hydrogen peroxide sensor based on a nanoporous gold electrode modified with platinum nanoparticles," Chemical Papers, vol. 68 , no. $4,2014$.

[99] R.-M. Song, Z. H. Li, P. J. Wei, X. L. Zhao, C. Chen, and Z. G. $\mathrm{Zhu}$, "Flexible hydrogen peroxide sensors based on platinum modified free-standing reduced graphene oxide paper," Applied Sciences, vol. 8, no. 6, p. 848, 2018.

[100] A. Safavi and F. Farjami, "Electrodeposition of gold-platinum alloy nanoparticles on ionic liquid-chitosan composite film and its application in fabricating an amperometric cholesterol biosensor," Biosensors and Bioelectronics, vol. 26, no. 5, pp. 2547-2552, 2011.

[101] M. R. Mahmoudian, W. J. Basirun, and Y. Alias, "A sensitive electrochemical $\mathrm{Hg} 2+$ ions sensor based on polypyrrole coated nanospherical platinum," RSC Advances, vol. 6, no. 43, pp. 36459-36466, 2016.

[102] S.-W. Jung, E. K. Lee, and S.-Y. Lee, "Communication-concentration-cell-type nafion-based potentiometric hydrogen sensors," ECS Journal of Solid State Science and Technology, vol. 7, no. 12, pp. Q239-Q241, 2018.

[103] R. Xi, S. H. Zhang, L. Zhang et al., "Electrodeposition of Pd-Pt nanocomposites on porous $\mathrm{GaN}$ for electrochemical nitrite sensing," Sensors, vol. 19, no. 3, p. 606, 2019.

[104] M. Govindhan, Z. Liu, and A. Chen, "Design and electrochemical study of platinum-based nanomaterials for sensitive detection of nitric oxide in biomedical applications," Nanomaterials, vol. 6, no. 11, p. 211, 2016. 
[105] M. R. Mahmoudian, Y. Alias, W. J. Basirun et al., "A sensitive electrochemical nitrate sensor based on polypyrrole coated palladium nanoclusters," Journal of Electroanalytical Chemistry, vol. 751, pp. 30-36, 2015.

[106] J. Sophia and G. Muralidharan, "Polyvinylpyrrolidone stabilized palladium nanospheres as simple and novel electrochemical sensor for amperometric hydrogen peroxide detection," Journal of Electroanalytical Chemistry, vol. 739, pp. 115-121, 2015.

[107] Y. Li, J. Z. Sun, C. Bian et al., "Copper nano-clusters prepared by one-step electrodeposition and its application on nitrate sensing," AIP Advances, vol. 5, no. 4, article 041312, 2015.

[108] S. A. Ghoto, M. Y. Khuhawar, T. M. Jahangir, and J. . D. Mangi, "Applications of copper nanoparticles for colorimetric detection of dithiocarbamate pesticides," Journal of Nanostructure in Chemistry, vol. 9, no. 2, pp. 77-93, 2019.

[109] Q. Li, F. Wu, M. Mao et al., "A dual-mode colorimetric sensor based on copper nanoparticles for the detection of mercury-(ii) ions," Analytical Methods, vol. 11, no. 31, pp. 4014-4021, 2019.

[110] D. Nunes, A. Pimentel, A. Gonçalves et al., "Metal oxide nanostructures for sensor applications," Semiconductor Science and Technology, vol. 34, no. 4, article 043001, 2019.

[111] A. Staerz, U. Weimar, and N. Barsan, "Understanding the potential of WO3 based sensors for breath analysis," Sensors, vol. 16, no. 11, p. 1815, 2016.

[112] X. Gao, Q. Zhou, Z. Lu, L. Xu, Q. Zhang, and W. Zeng, "Synthesis of $\mathrm{Cr} 2 \mathrm{O} 3$ nanoparticle-coated $\mathrm{SnO} 2$ nanofibers and C2H2 sensing properties," Frontiers in Materials, vol. 6, no. $163,2019$.

[113] H. Chen, R. Bo, A. Shrestha et al., "NiO-ZnO nanoheterojunction networks for room-temperature volatile organic compounds sensing," Advanced Optical Materials, vol. 6, no. 22, article 1800677, 2018.

[114] H. Wang, D. Wang, L. Tian et al., "Graphene-like porous $\mathrm{ZnO} /$ graphene oxide nanosheets for high-performance acetone vapor detection," Molecules, vol. 24, no. 3, p. 522, 2019.

[115] K. Zhang, S. Qin, P. Tang, Y. Feng, and D. Li, "Ultra-sensitive ethanol gas sensors based on nanosheet-assembled hierarchical ZnO-In2O3 heterostructures," Journal of Hazardous Materials, vol. 391, article 122191, 2020.

[116] S. J. Choi, I. Lee, B. H. Jang et al., "Selective diagnosis of diabetes using Pt-functionalized WO3Hemitube networks as a sensing layer of acetone in exhaled breath," Analytical Chemistry, vol. 85, no. 3, pp. 1792-1796, 2013.

[117] S. J. Choi, F. Fuchs, R. Demadrille et al., "Fast responding exhaled-breath sensors using WO3 hemitubes functionalized by graphene-based electronic sensitizers for diagnosis of diseases," ACS Applied Materials \& Interfaces, vol. 6, no. 12, pp. 9061-9070, 2014.

[118] S. J. Choi, B. H. Jang, S. J. Lee, B. K. Min, A. Rothschild, and I. D. Kim, "Selective detection of acetone and hydrogen sulfide for the diagnosis of diabetes and halitosis using $\mathrm{SnO}(2)$ nanofibers functionalized with reduced graphene oxide nanosheets," ACS Applied Materials \& Interfaces, vol. 6, no. 4, pp. 2588-2597, 2014.

[119] K. Wan, J. Yang, D. Wang, and X. Wang, "Graphene oxide@3D hierarchical SnO2 nanofiber/nanosheets nanocomposites for highly sensitive and low-temperature formaldehyde detection," Molecules, vol. 25, no. 1, p. 35, 2020.

[120] D. Wang, L. Tian, H. Li et al., "Mesoporous ultrathin SnO2Nanosheets in situ modified by graphene oxide for extraordi- nary formaldehyde detection at low temperatures," ACS Applied Materials \& Interfaces, vol. 11, no. 13, pp. 1280812818, 2019.

[121] K. Wan, D. Wang, F. Wang et al., "Hierarchical In2O3@SnO2Core-Shell Nanofiber for high efficiency formaldehyde detection," ACS Applied Materials \& Interfaces, vol. 11, no. 48, pp. 45214-45225, 2019.

[122] A. Eatemadi, H. Daraee, H. Karimkhanloo et al., "Carbon nanotubes: properties, synthesis, purification, and medical applications," Nanoscale Research Letters, vol. 9, no. 1, p. 393, 2014.

[123] L. Camilli and M. Passacantando, "Advances on sensors based on carbon nanotubes," Chemosensors, vol. 6, no. 4, p. 62, 2018.

[124] R. Andrews, D. Jacques, D. Qian, and T. Rantell, "Multiwall carbon nanotubes: synthesis and application," Accounts of Chemical Research, vol. 35, no. 12, pp. 1008-1017, 2002.

[125] J. F. Colomer, C. Stephan, S. Lefrant et al., "Large-scale synthesis of single-wall carbon nanotubes by catalytic chemical vapor deposition (CCVD) method," Chemical Physics Letters, vol. 317, no. 1-2, pp. 83-89, 2000.

[126] C. Ursino, R. Castro-Muñoz, E. Drioli, L. Gzara, M. Albeirutty, and A. Figoli, "Progress of nanocomposite membranes for water treatment," Membranes, vol. 8, no. 2, p. 18, 2018.

[127] I. V. Zaporotskova, N. P. Boroznina, Y. N. Parkhomenko, and L. V. Kozhitov, "Carbon nanotubes: sensor properties. A review," Modern Electronic Materials, vol. 2, no. 4, pp. 95$105,2016$.

[128] K. F. Akhmadishina, I. I. Bobrinetskii, I. A. Komarov et al., "Flexible biological sensors based on carbon nanotube films," Nanotechnologies in Russia, vol. 8, no. 11-12, pp. 721-726, 2013.

[129] Y. Wang and J. T. W. Yeow, "A review of carbon nanotubesbased gas sensors," Journal of Sensors, vol. 2009, Article ID 493904, 24 pages, 2009.

[130] X. Zhang, H. Cui, Y. Gui, and J. Tang, "Mechanism and application of carbon nanotube sensors in SF6 decomposed production detection: a review," Nanoscale Research Letters, vol. 12, no. 1, p. 177, 2017.

[131] J. Suehiro, G. Zhou, and M. Hara, "Fabrication of a carbon nanotube-based gas sensor using dielectrophoresis and its application for ammonia detection by impedance spectroscopy," Journal of Physics D: Applied Physics, vol. 36, no. 21, pp. L109-L114, 2003.

[132] S. K. Vashist, D. Zheng, K. al-Rubeaan, J. H. T. Luong, and F. S. Sheu, "Advances in carbon nanotube based electrochemical sensors for bioanalytical applications," Biotechnology Advances, vol. 29, no. 2, pp. 169-188, 2011.

[133] K. A. Williams and P. C. Eklund, "Monte Carlo simulations of $\mathrm{H} 2$ physisorption in finite-diameter carbon nanotube ropes," Chemical Physics Letters, vol. 320, no. 3-4, pp. 352358, 2000.

[134] C. S. Yeung, L. V. Liu, and Y. A. Wang, “Adsorption of small gas molecules onto Pt-doped single-walled carbon nanotubes," The Journal of Physical Chemistry C, vol. 112, no. 19 , pp. 7401-7411, 2008.

[135] M. Yoosefian, M. Zahedi, A. Mola, and S. Naserian, “A DFT comparative study of single and double $\mathrm{SO} 2$ adsorption on Pt-doped and Au-doped single-walled carbon nanotube," Applied Surface Science, vol. 349, pp. 864-869, 2015. 
[136] X. Zhou, W. Q. Tian, and X.-L. Wang, "Adsorption sensitivity of Pd-doped SWCNTs to small gas molecules," Sensors and Actuators B: Chemical, vol. 151, no. 1, pp. 56-64, 2010.

[137] S. Seenithurai, R. Kodi Pandyan, S. Vinodh Kumar, and M. Mahendran, "H2 adsorption in $\mathrm{Ni}$ and passivated $\mathrm{Ni}$ doped $4 \AA$ single walled carbon nanotube," International Journal of Hydrogen Energy, vol. 38, no. 18, pp. 7376-7381, 2013.

[138] H. Nakano, H. Ohta, A. Yokoe, K. Doi, and A. Tachibana, "First-principle molecular-dynamics study of hydrogen adsorption on an aluminum-doped carbon nanotube," Journal of Power Sources, vol. 163, no. 1, pp. 125-134, 2006.

[139] Z. Zhou, X. Gao, J. Yan, and D. Song, "Doping effects of B and $\mathrm{N}$ on hydrogen adsorption in single-walled carbon nanotubes through density functional calculations," Carbon, vol. 44, no. 5, pp. 939-947, 2006.

[140] X. Zhang, Y. Gui, and Z. Dai, “A simulation of Pd-doped SWCNTs used to detect SF6 decomposition components under partial discharge," Applied Surface Science, vol. 315, pp. 196-202, 2014.

[141] X. Zhang, Z. Dai, Q. Chen, and J. Tang, "A DFT study of SO2and $\mathrm{H} 2 \mathrm{~S}$ gas adsorption on Au-doped single-walled carbon nanotubes," Physica Scripta, vol. 89, no. 6, article 065803, 2014.

[142] X. Zhang, B. Feng, J. Zhang, J. Tang, and W. Liu, "Gas sensing response of $\mathrm{NiCl} 2$-doped carbon nanotubes to decomposition products of SF6 gas due to partial discharge," Power System Technology, vol. 35, no. 10, pp. 189-193, 2011.

[143] X. Zhang, B. Yang, Z. Dai, and C. Luo, "The gas response of hydroxyl modified SWCNTs and carboxyl modified SWCNTs to H2S and SO2," Electrical Review, vol. 88, no. 7B, pp. 311-314, 2012.

[144] X. Zhang, F. Meng, and B. Yang, "Use of hydroxyl-modified carbon nanotubes for detecting SF6decomposition products under partial discharge in gas insulated switchgear," IEEE Transactions on Dielectrics and Electrical Insulation, vol. 20, no. 6, pp. 2246-2253, 2013.

[145] T. Zhang, S. Mubeen, E. Bekyarova et al., "Poly(m-aminobenzene sulfonic acid) functionalized single-walled carbon nanotubes based gas sensor," Nanotechnology, vol. 18, no. 16, article 165504, 2007.

[146] I. Sayago, H. Santos, M. Horrillo et al., "Carbon nanotube networks as gas sensors for NO2 detection," Talanta, vol. 77, no. 2, pp. 758-764, 2008.

[147] A. N. Naje, R. R. Ibraheem, and F. T. Ibrahim, "Parametric analysis of NO2 gas sensor based on carbon nanotubes," Photonic Sensors, vol. 6, no. 2, pp. 153-157, 2016.

[148] A. Kausar, "Detection of environmentally hazardous nitrogen oxide pollutants using polythiophene derivative/carbon nanotube-based nanocomposite," Frontiers in Science, vol. 1, no. 1, pp. 23-26, 2017.

[149] F. Rigoni, S. Tognolini, P. Borghetti et al., "Enhancing the sensitivity of chemiresistor gas sensors based on pristine carbon nanotubes to detect low-ppb ammonia concentrations in the environment," Analyst, vol. 138, no. 24, pp. 7392-7399, 2013.

[150] F. Rigoni, G. Drera, S. Pagliara, A. Goldoni, and L. Sangaletti, "High sensitivity, moisture selective, ammonia gas sensors based on single-walled carbon nanotubes functionalized with indium tin oxide nanoparticles," Carbon, vol. 80, pp. 356363, 2014.
[151] L. A. Panes-Ruiz, M. Shaygan, Y. Fu et al., "Toward highly sensitive and energy efficient ammonia gas detection with modified single-walled carbon nanotubes at room temperature," ACS Sensors, vol. 3, no. 1, pp. 79-86, 2017.

[152] H. Lee, G. Shaker, K. Naishadham et al., "Carbon-nanotube loaded antenna-based Ammonia gas sensor," IEEE Transactions on Microwave Theory and Techniques, vol. 59, no. 10, pp. 2665-2673, 2011.

[153] W. Zhao, D. W. H. Fam, Z. Yin et al., "A carbon monoxide gas sensor using oxygen plasma modified carbon nanotubes," Nanotechnology, vol. 23, no. 42, p. 425502, 2012.

[154] A. M. Souza, A. R. Rocha, A. Fazzio, and A. J. R. da Silva, “Abinitiocalculations for a realistic sensor: a study of CO sensors based on nitrogen-rich carbon nanotubes," AIP Advances, vol. 2, no. 3, article 032115, 2012.

[155] M. Moradi, A. Aghakhani, and M. J. Eshraghi, "Dispersioncorrected DFT study on the carbon monoxide sensing by B2C nanotubes: effects of dopant and interferences," Structural Chemistry, vol. 27, no. 2, pp. 535-542, 2016.

[156] G. Zhang, H. L. Tai, G. Z. Xie, Y. D. Jiang, and Y. Zhou, “A carbon monoxide sensor based on single-walled carbon nanotubes doped with copper chloride," SCIENCE CHINA Technological Sciences, vol. 56, no. 10, pp. 2576-2580, 2013.

[157] S. F. Liu, S. Lin, and T. M. Swager, “An organocobalt-carbon nanotube chemiresistive carbon monoxide detector," ACS Sensors, vol. 1, no. 4, pp. 354-357, 2016.

[158] L. H. H. Hsu, E. Hoque, P. Kruse, and P. Ravi Selvaganapathy, "A carbon nanotube based resettable sensor for measuring free chlorine in drinking water," Applied Physics Letters, vol. 106, no. 6, article 063102, 2015.

[159] J. Muñoz, F. Céspedes, and M. Baeza, "Modified multiwalled carbon nanotube/epoxy amperometric nanocomposite sensors with $\mathrm{CuO}$ nanoparticles for electrocatalytic detection of free chlorine," Microchemical Journal, vol. 122, pp. 189-196, 2015.

[160] R. Olivé-Monllau, A. Pereira, J. Bartrolí, M. Baeza, and F. Céspedes, "Highly sensitive CNT composite amperometric sensors integrated in an automated flow system for the determination of free chlorine in waters," Talanta, vol. 81, no. 4-5, pp. 1593-1598, 2010.

[161] N. Kumar and L. S. B. Upadhyay, "19 - Polymeric gels for biosensing applications," in Polymeric Gels, K. Pal and I. Banerjee, Eds., pp. 487-503, Woodhead Publishing, 2018.

[162] P. Parkhey and S. V. Mohan, "Chapter 6.1 - Biosensing applications of microbial fuel cell: approach toward miniaturization," in Microbial Electrochemical Technology, S. V. Mohan, S. Varjani, and A. Pandey, Eds., pp. 977-997, Elsevier, 2019.

[163] C.-M. Tîlmaciu and M. C. Morris, "Carbon nanotube biosensors," Frontiers in Chemistry, vol. 3, pp. 59-59, 2015.

[164] E. Arkan, R. Saber, Z. Karimi, and M. Shamsipur, "A novel antibody-antigen based impedimetric immunosensor for low level detection of HER2 in serum samples of breast cancer patients via modification of a gold nanoparticles decorated multiwall carbon nanotube-ionic liquid electrode," Analytica Chimica Acta, vol. 874, pp. 66-74, 2015.

[165] M. M. Barsan, M. E. Ghica, and C. M. A. Brett, "Electrochemical sensors and biosensors based on redox polymer/carbon nanotube modified electrodes: a review," Analytica Chimica Acta, vol. 881, pp. 1-23, 2015.

[166] M. D. Rubianes and G. A. Rivas, "Carbon nanotubes paste electrode," Electrochemistry Communications, vol. 5, no. 8, pp. 689-694, 2003. 
[167] V. Pifferi, M. M. Barsan, M. E. Ghica, L. Falciola, and C. M. A. Brett, "Synthesis, characterization and influence of poly(brilliant green) on the performance of different electrode architectures based on carbon nanotubes and poly(3,4-ethylenedioxythiophene)," Electrochimica Acta, vol. 98, pp. 199-207, 2013.

[168] M. Pedano and G. A. Rivas, "Adsorption and electrooxidation of nucleic acids at carbon nanotubes paste electrodes," Electrochemistry Communications, vol. 6, no. 1, pp. 10-16, 2004.

[169] H.-J. Liu, D.-W. Yang, and H.-H. Liu, "A hydrogen peroxide sensor based on the nanocomposites of poly(brilliant cresyl blue) and single walled-carbon nanotubes," Analytical Methods, vol. 4, no. 5, pp. 1421-1426, 2012.

[170] M. E. Ghica, Y. Wintersteller, and C. M. A. Brett, "Poly(brilliant green)/carbon nanotube-modified carbon film electrodes and application as sensors," Journal of Solid State Electrochemistry, vol. 17, no. 6, pp. 1571-1580, 2013.

[171] M. E. Ghica and C. M. A. Brett, "Poly(brilliant green) and poly(thionine) modified carbon nanotube coated carbon film electrodes for glucose and uric acid biosensors," Talanta, vol. 130, pp. 198-206, 2014.

[172] A. de la Zerda, Z. Liu, S. Bodapati et al., "Ultrahigh sensitivity carbon nanotube agents for photoacoustic molecular imaging in living mice," Nano Letters, vol. 10, no. 6, pp. 2168-2172, 2010.

[173] X. Wang, C. Wang, K. Qu et al., "Ultrasensitive and selective detection of a prognostic indicator in early-stage cancer using graphene oxide and carbon nanotubes," Advanced Functional Materials, vol. 20, no. 22, pp. 3967-3971, 2010.

[174] M. Rousehttps://whatis.techtarget.com/definition/ photosensor.

[175] M. Navvab, C. Burattini, F. Bisegna, and F. Gugliermetti, "Chapter 8 - Building automation for energy efficiency," in Handbook of Energy Efficiency in Buildings, F. Asdrubali and U. Desideri, Eds., pp. 597-673, Butterworth-Heinemann, 2019.

[176] C.-M. Lin and W. Fang, "Batch-fabricated flexible carbon nanotubes' photosensor array," Nanotechnology, vol. 20, no. 46, p. 465502, 2009.

[177] M. Yang, J. Xu, J. Wei, J. L. Sun, W. Liu, and J. L. Zhu, "Fabrication of double-walled carbon nanotube film/Cu2O nanoparticle film/TiO2nanotube array heterojunctions for photosensors," Applied Physics Letters, vol. 100, no. 25, article 253113, 2012.

[178] X. Wu, B. Zhou, J. Zhou, Y. Chen, Y. Chu, and J. Huang, "Distinguishable detection of ultraviolet, visible, and infrared spectrum with high-responsivity perovskite-based flexible photosensors," Small, vol. 14, no. 19, article 1800527, 2018.

[179] HBMhttps://www.hbm.com/en/7646/what-is-a-pressuresensor/.

[180] A. Cao, P. L. Dickrell, W. G. Sawyer, M. N. Ghasemi-Nejhad, and P. M. Ajayan, "Super-compressible foamlike carbon nanotube films," Science, vol. 310, no. 5752, pp. 1307-1310, 2005.

[181] V. L. Pushparaj, L. Ci, S. Sreekala et al., "Effects of compressive strains on electrical conductivities of a macroscale carbon nanotube block," Applied Physics Letters, vol. 91, no. 15 , p. 153116, 2007.

[182] H.-M. So, J. W. Sim, J. Kwon, J. Yun, S. Baik, and W. S. Chang, "Carbon nanotube based pressure sensor for flexible electronics," Materials Research Bulletin, vol. 48, no. 12, pp. 5036-5039, 2013.
[183] S. M. Doshi and E. T. Thostenson, "Thin and flexible carbon nanotube-based pressure sensors with ultrawide sensing range," ACS sensors, vol. 3, no. 7, pp. 1276-1282, 2018.

[184] M. Adamczak, G. Kamińska, and J. Bohdziewicz, "Preparation of polymer membranes by in situ interfacial polymerization," International Journal of Polymer Science, vol. 2019, Article ID 6217924, 13 pages, 2019.

[185] F. R. Passador, A. Ruvolo-Filho, and L. A. Pessan, "7 - Nanocomposites of polymer matrices and lamellar clays," in Nanostructures, A. L. Róz, Ed., pp. 187-207, William Andrew Publishing, 2017.

[186] Y. Ying, W. Ying, Q. Li et al., "Recent advances of nanomaterial-based membrane for water purification," Applied Materials Today, vol. 7, pp. 144-158, 2017.

[187] T. C. Huang, J. M. Yeh, and C. Y. Lai, "18 - Polymer nanocomposite coatings," in Advances in Polymer Nanocomposites, F. Gao, Ed., pp. 605-638, Woodhead Publishing, 2012.

[188] H. D. Beyene and T. G. Ambaye, "Application of sustainable nanocomposites for water purification process," in Sustainable Polymer Composites and Nanocomposites, Inamuddin, pp. 387-412, Springer International Publishing, Cham, 2019.

[189] T. Tian, X. Shi, L. Cheng et al., "Graphene-based nanocomposite as an effective, multifunctional, and recyclable antibacterial agent," ACS Applied Materials \& Interfaces, vol. 6, no. 11, pp. 8542-8548, 2014.

[190] S. Zhao, Z. Wang, X. Wei et al., "Performance improvement of polysulfone ultrafiltration membrane using welldispersed polyaniline-poly(vinylpyrrolidone) nanocomposite as the additive," Industrial \& Engineering Chemistry Research, vol. 51, no. 12, pp. 4661-4672, 2012.

[191] J. Hyun, S. Min, I. Jun, J. Won, Y. Hwa, and Mohammad, "Carbon nanotube embedded multi-functional polymer nanocomposites, Nanocomposites," in Nanocomposites: New Trends and Developments, F. Ebrahimi, Ed., pp. 17-35, IntetechOpen, 2012.

[192] E. I. Akpan, X. Shen, B. Wetzel, and K. Friedrich, "2 - Design and synthesis of polymer nanocomposites," in Polymer Composites with Functionalized Nanoparticles, K. Pielichowski and T. M. Majka, Eds., pp. 47-83, Elsevier, 2019.

[193] T. Hanemann and D. V. Szabó, "Polymer-nanoparticle composites: from synthesis to modern applications," Materials, vol. 3, no. 6, pp. 3468-3517, 2010.

[194] B. Tang, Z. Huo, and P. Wu, "Study on a novel polyester composite nanofiltration membrane by interfacial polymerization of triethanolamine (TEOA) and trimesoyl chloride (TMC)," Journal of Membrane Science, vol. 320, no. 1-2, pp. 198205, 2008

[195] B. John, "Polymer nanocomposite-based electrochemical sensors and biosensors," in Nanorods and Nanocomposites, IntechOpen, 2020.

[196] R. Devi, M. Thakur, and C. S. Pundir, "Construction and application of an amperometric xanthine biosensor based on zinc oxide nanoparticles-polypyrrole composite film," Biosensors \& Bioelectronics, vol. 26, no. 8, pp. 3420-3426, 2011.

[197] L. Xing, Q. Rong, and Z. Ma, "Non-enzymatic electrochemical sensing of hydrogen peroxide based on polypyrrole/platinum nanocomposites," Sensors and Actuators B: Chemical, vol. 221, pp. 242-247, 2015.

[198] Z. Yu, H. Li, X. Zhang et al., "Facile synthesis of NiCo2O4@Polyaniline core-shell nanocomposite for sensitive determination 
of glucose," Biosensors \& Bioelectronics, vol. 75, pp. 161-165, 2016.

[199] Y. Fan, J. H. Liu, C. P. Yang, M. Yu, and P. Liu, "Graphenepolyaniline composite film modified electrode for voltammetric determination of 4-aminophenol," Sensors and Actuators B: Chemical, vol. 157, no. 2, pp. 669-674, 2011.

[200] K. Radhapyari, P. Kotoky, M. R. Das, and R. Khan, "Graphene-polyaniline nanocomposite based biosensor for detection of antimalarial drug artesunate in pharmaceutical formulation and biological fluids," Talanta, vol. 111, pp. 47-53, 2013.

[201] R. Jain, D. C. Tiwari, and S. Shrivastava, "A sensitive voltammetric sensor based on synergistic effect of polyaniline and zirconia nanocomposite film for quantification of proton pump inhibitor esomeprazole," Journal of the Electrochemical Society, vol. 161, no. 4, pp. B39-B44, 2014.

[202] X. Ma, T. Miao, W. Zhu et al., "Electrochemical detection of nitrite based on glassy carbon electrode modified with goldpolyaniline-graphene nanocomposites," RSC Advances, vol. 4, no. 101, pp. 57842-57849, 2014.

[203] Y.-S. Gao, J. K. Xu, L. M. Lu et al., “Overoxidized polypyrrole/graphene nanocomposite with good electrochemical performance as novel electrode material for the detection of adenine and guanine," Biosensors and Bioelectronics, vol. 62, pp. 261-267, 2014.

[204] H. Mao, J. Liang, H. Zhang et al., "Poly(ionic liquids) functionalized polypyrrole/graphene oxide nanosheets for electrochemical sensor to detect dopamine in the presence of ascorbic acid," Biosensors and Bioelectronics, vol. 70, pp. 289-298, 2015.

[205] L. Lu, O. Zhang, J. Xu et al., "A facile one-step redox route for the synthesis of graphene/poly (3,4-ethylenedioxythiophene) nanocomposite and their applications in biosensing," Sensors and Actuators B: Chemical, vol. 181, pp. 567-574, 2013.

[206] R. Jain and S. Shrivastava, "A graphene-polyanilineBi2O3hybrid film sensor for voltammetric quantification of anti-inflammatory drug Etodolac," Journal of the Electrochemical Society, vol. 161, no. 4, pp. H189-H194, 2014.

[207] X. Tan, L. Zhang, X. Deng, L. Miao, H. Li, and G. zheng, "Redox active molybdophosphate produced by $\mathrm{Cu} 3(\mathrm{PO} 4) 2-$ nanospheres for enhancing enzyme-free electrochemical immunoassay of C-reactive protein," New Journal of Chemistry, vol. 41, no. 20, pp. 11867-11871, 2017. 